\title{
سلسلة التوريد المحلية والتجارة الداخلية في مصر في ظل جائحة كورونـا
}

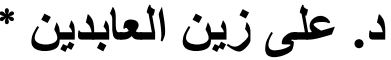

أصسبحت جائحة كوفيد-19 الناتجة عن فيروس كورونا المسـتجد أو SARS-CoV-2 حديث العالم، لما لهذه الجائحة من خصـائص جعلت التحكم فيها يصـب على أكثر الأنظمة الصـحية

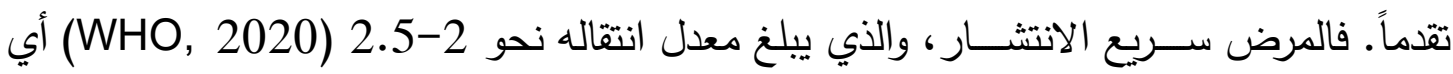
ينتقل من الفرد المصاب إلى شخصين آخرين على الأقل، انتقل إلى معظم بلدان العالم، وتسبب في تعطل دورات الإنتاج في معظم البلدان الصناعية الكبرى.

وقد واجهت سـلســلة التوريد العالمية منذ تفشى جائحة كوفيد-19 مشـكلات نتجت عن إغلاق المصـانع، وزيادة الطلب على السـلع الأسـاسـية، والثــراء والتخزين المفرط من قبل المستهلكين الناجم عن الذعر ، فضــاً عن تغير تفضــيلات المسـتهلك الذي أصــبح أكثر ميلاً للثـراء ودفع الفواتير عبر الإنترنت تقليلاً للبقاء خارج المنزل. ولذا فإن مرونة سلسـلة التوريد المحلية والعالمية أصـبحت على المحك لتبقى صـامدة في ظل أزمة عالمية مسـمرة إلى أمدٍ غير معلوم. وأصـبح التحدي الآن لسلسلة التوريد هو كيفية الحفاظ على استمرارية الأعمال، وفي نفس الوقت الحفاظ (World Economic Forum, على العاملين، وتحسين قدرة نظم التوريد على الدقاومة والبقاء $.2020)$

ويمثل قطاع التجارة الداخلية حوالي 14.69٪ من الناتج المحلي الإجمالي بالأســعار الثابتة للنصــف الثاني من العام 2020/2019 (البنك المركزى المصــرى، 2020). وبذلك يُعد هذا القطاع ثاني أهم القطاعات الاقتصـادية في مصـر بعد قطاع الصـناعات التحويلية المسئول عن 17.12 من الناتج المحلي الإجمالي المصــري خلال ذات الفترة. ويتبوأ قطاع تجارة الجملة

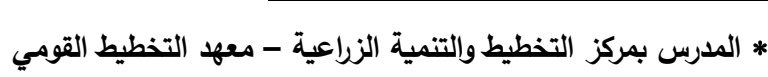

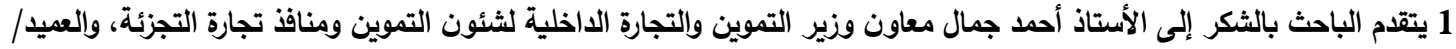

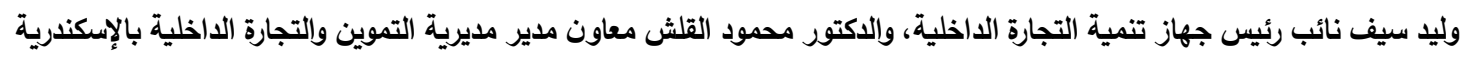

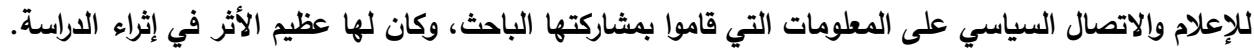


والتجزئة المرتبة الأولى كأكثر القطاعات الاقتصـــــادية مســـاهمةً في الناتج المحلي الإجمالي الخاص، في حين لا تبلغ مساهمته في الناتج المحلي العام سوى 2.66\% فقط خلال نفس الفترة (البنك المركزى المصـرى، 2020). وعلى الرغم من أهمية قطاع الجملة والتجزئة في الاقتصـاد

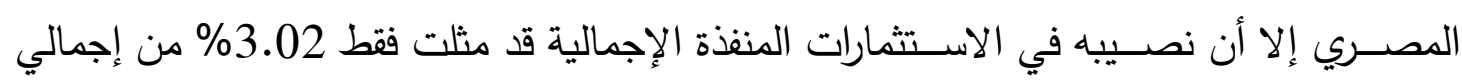
الاسـتثمارات المنفذة خلال النصـف الثاني من العام 2020/2019 (البنك المركزى المصـرى، لإل .$(2020$

وتشـارك كلٍ من تجارة الجملة وتجارة التجزئة المنظمة بنحو 5.3\%، 0.6\% في القيمة المضـافة الصــافية لثــركات القطاع الخاص المنظم على الترتيب عام 2017. كما يُعدان مسـئولان عن 2.5\%، 0.5\% من الأجور ، ويعمل بهـا 3.4\%، 1.3\% من العاملين في القطاع الخـاص المنظم على الترتيب عام 2017 (الجهاز المركزي للتعبئة العامة والإحصاء، 2019).

وتبحث هذه الورقة تداعيات جائحة كوفيد-19 على سـلسـلة التوريد المحلية والتجارة الداخلية في مصـر وفقاً للسـيناريوهات الثلاثة التي تتبناها الدولة المصـرية ممثلة في وزارة التخطيط والتتمية الاقتصادية لتوقيت احتواء الأزمة، وهي:

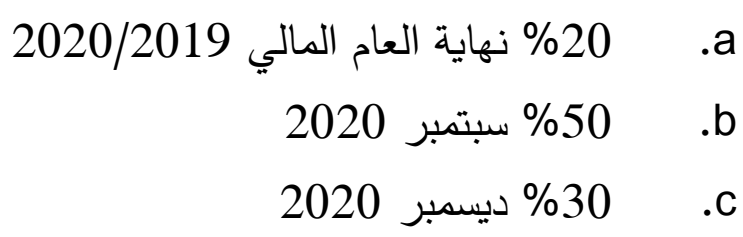

المنهجية: اعتمد تقرير للمنتسى الاقتصادي العالمي لبحث وسائل الخروج من أزمة جائحة كوفيد19 على مستوى التصنيع وسلسلة التوريد على تغذية راجعة من أكثر من 400 تتفيذي يعملون في إدارة سلسلة التوريد للقطاعات الصناعية المختلفة (World Economic Forum, 2020). وفي دراسة أخرى، ونظراً لعدم توفر بيانات، اعتمد المركز المصري للدراسات الاقتصادية عند تقييمه لتداعيات الأزمة على تجارة تجزئة البقالة على تحليل صدمات العرض والطلب لتون المرتبطة بدورة الأزمة، وذلك اعتماداً على التجارب التي مر بها القطاع خلال ثورة الخامس والعشرون من لإنه يناير عام 2011، وعندما تم تحرير سعر الصرف عام 2016 (المركز المصرى للدراسات الاقتصادية، 2020). 
أما هذه الورقة فقد اعتمدت على تحليل الأرقام القياسـية لأسـعار المسـتهلكين والمنتجين المتاحة خلال أثهر الأزمة كي تعكس مدى تأثر الطلب والعرض للمجموعات السلعية المختلفة في مصر بجائحة كوفيد-19. بالإضـــــافة إلى تحليل مدى تأثر معدلات النمو لقطاع التجارة الداخلية بالأزمات الخارجية والداخلية خلال فترة تبدأ من العام المالي 2008/2007 إلى 2020/2019.

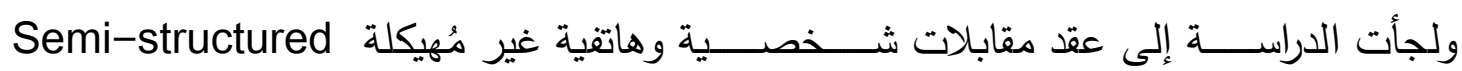
interviews تليفونية أخرى مع فاعلين في سـلسـلة توريد الغذاء للوقوف على مدى تأثرهم بالجائحة، وتوقعاتهم لأداء السوق في حال استمرارها. كما أوجزت الدراسـة في عرضٍ مرجعي مكثفٍ تأثير كوفيد-19 على سـلســلة التوريد العالمية، وكذا الآليات التي من شـأنها أن تُخرج سـلســلة التوريد من هذه الجائحة بأقل خسائر ، وربما أكثر قوة.

تتكون هذه الورقة من خمسة أجزاء بالإضافة إلى المقدمة والخاتمة، وهي: 1. سلسلة التوريد العالمية وآليات الخروج من الأزمة- عرض مرجعي. 2. بعض مظاهر تأثير جائحة كوفيد-19 على سلسلة التوريد المحلية في مصر . 3. سلسلة توريد الغذاء في مصر في ظل جائحة كوفيد-19. 4. كيف ستؤثر جائحة كوفيد-19 على نمو التجارة الداخلية في مصر؟. 5. التدخلات الحالية والمقترحة لدفع النمو في التجارة الداخلية في مصر. 1. سلسلة التوريد العالمية وأليات الخروج من الأزمة- عرض مرجعي سـلســلة التوريد هي مجموعة من المؤسـسـات والعمليات التي يمر المنتج من خلالها ابتداءً من مصسادره الأولية حتى وصـوله إلى المستهلك النهائي. ويتوقف طول السلسلة، وعدد الروابط بينها على نوع المنتج (Schoenfeldt, 2008).

\section{1. تأثير جائحة كوفيد-19 على سلسلة التوريا العالمية:}

تعددت تأثيرات جائحة كوفيد-19 على كفاءة سلسلة التوريد وأدائها لما تسببت فيه من إبطاء في الخدمات اللوجستية، وتعطيل في مسارات تدفق مستلزمات الإنتاج والمنتجات الوسيطة والنهائية. 


\subsection{1.التأثير على الثحن والخدمات اللوجستية:}

ساهم تأخير الرحلات أو إلغائها نتيجة الجائحة في الحد من قدرة الثحن الجوي، وجعلت مسئولي المشـتريات يواجهون صـعوبات في متابعة التغيرات السـريعة في مطارات المنشـأ والوجهة وفي الموانئ البحرية والنقل البري لتحديد الاختيار الأفضـل لثــن منتجاتهم. كما أصـبح إعادة توجيه

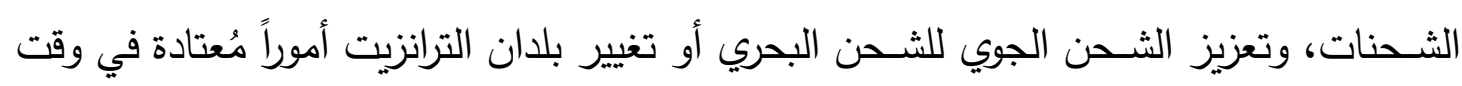

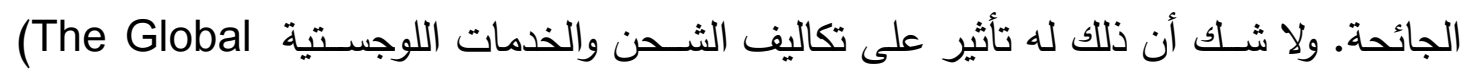

.Fund, 2020)

1.1.2.اضطرابات سلسلة التوريد:

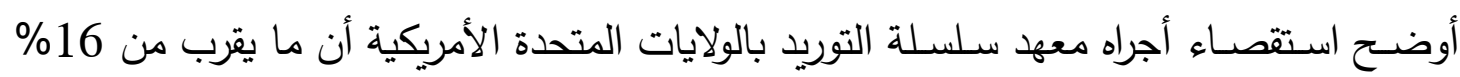
من الثــركات قد انخفضـــت أرباحها نتيجة تضــــاعف أوقات التوريد، ونقص الخيارات المتاحة للشحن الجوي والبحري (Boyd, 2020). ويوجد قلق دولي متزايد بشأن العجز في سلسلة التوريد من معدات الحماية الثخصية ضد مرض كوفيد-19، وشملت الحلول للتغلب على ذلك العجز في جمهورية إيرلندا إعادة معالجة واســخدام معدات الحماية الثـخصـية من خلال آليات التعقيم والتطهير المناســة (Rowan \& Laffey, 2020). كما تســبيت الجائحة في تعطيل حملات تطعيم الأطفال، وأداء الخدمات الطبية الهامة إلى الســـكان خاصــــةً في البلدان ذات الدخل المنخفض والمتوسط (Nelson, 2020). 1.1.3 نتج عن جائحة كوفيد-19 ما أطلق عليه (MaKenzie, 2020) "الصـــحاري الصـــنـاعية" عندما انخفض الناتج الكلي لمدينة أو منطقة أو دولة بأكملها نتيجة الإجراءات الاحترازية التي تم اتخاذها، واقتصـار التوريد على العناصـر الأسـاسية للحياة من مواد غذائية ومستلزمات طبية.

1.1.4.أكثر قطاعات سلسلة التوريد العالمية تأثراً بالجائحة:

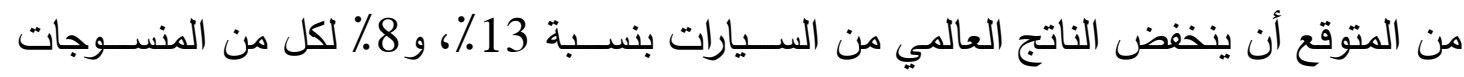

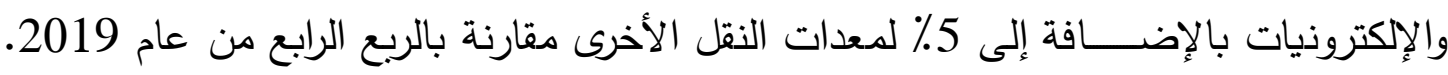
(MaKenzie, 2020) 


\subsection{5.أثر كوفيد-19 على سلسلة توريد الغذاء في البلدان النامية:}

من المرجح أن يزيد كوفيد-19 من أســـعار الغذاء، حيث ســـيتـــبـ الحظر المفروض على الخدمات اللوجستية في زيادة تكاليف المعاملات، وبالتالي سيؤدي إلى زيادة في أسعار المستهلك (Bellemare, 2015). وفيما يتعلق بسـلامة الغذاء، يجب أن توجه الموارد البشـرية النادرة إلى له الأماكن الحرجة، وإلى السوق المحلي أكثر من التصدير، مع الحاجة إلى تخفيف اللوائح الداخلية

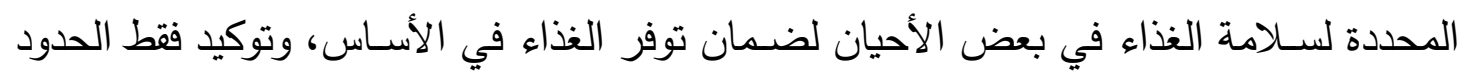
المقبولة لسلامته (Keogh, 2020).

$$
\text { 1.1.6 أثر كوفيد-19 على الزراعة: }
$$

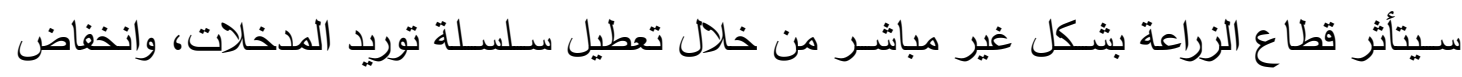

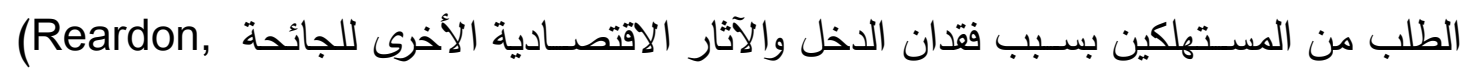
وأصبح من الضروري الحفاظ على الوحدات البيولوجية. Bellemare, \& Zilberman, 2020) الكُنتجة للبروتين الحيواني، لأن إدارة الأزمة ســتـعقد في حال اكتثــاف حالات إصــابة داخل

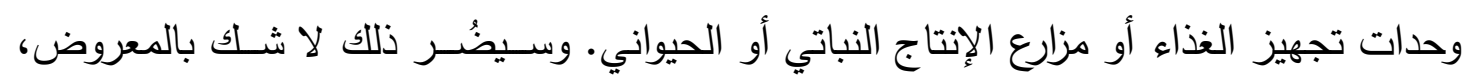
ومن ثم سيؤثر على السعر (Caldwell, 2020).

\section{2. سلسلة التوريد: آليات الخروج من الأزمة: أولاً: على مستوى الثركات:

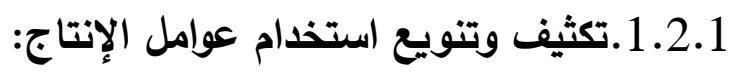

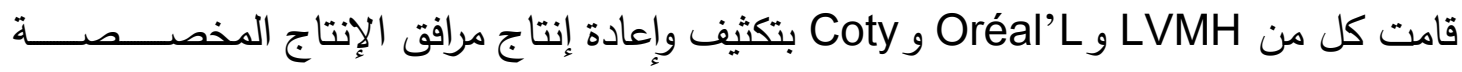
للعطور والمواد الهلامية من أجل إنتاج معقم اليدين، وهو المورد القيم الذي يســــاعد في إنقاذ الأرواح، وفي نفس الوقت، فإن هذه الخطوة ســــاعدت في الحفاظ على العمال والمرافق عندما انحصر الطلب عن السلع الفاخرة (Seifert \& Markoff, 2020). 
1.2.2 توسيع مصادر التوريد:

يتوقع (Seifert \& Markoff, 2020) أن بعض الثـركات ستقوم بالتضـية بالرشـاقة والمرونة في توفير المنتجات في مقابل تخفيض التكاليف، وسـيقومون بتوحيد الإنتاج وتوسـيع مصــادر التوريد أثناء الأزمة.

1.2.3 زيادة كفاءة استخدام الموارد:

على الثـركات العاملة في سلسـلة التوريد استخدام التتنيات التكنولوجية الحديثة من أجل ضـمان تحقيق أعلى كفاءة ممكنة في إسـتغلال الموارد في عالمٍ أصـبحت فيه الدول جميعها شـبه منغلقة على نفهـا. فعلى الثركات أن تتفادى تحميل الشاحنات دون أن تكون ممتلئة عن أخرها. وعلى المتتافسين أن يتعاونوا للتسيق فيما يتعلق بالتوريدات من المواد الخام، والمعروض من المنتجات

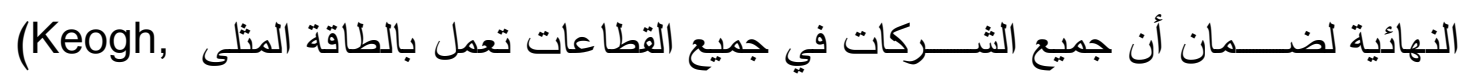

اتخاذ الإجراءات الكفيلة بضمان استمرارية الأعمال وحماية الموظفين:

على القادة الفاعلين في سـســلة التوريد أن يتخذوا إجراءات اسـتباقية لحماية الموظفين، وضـمان

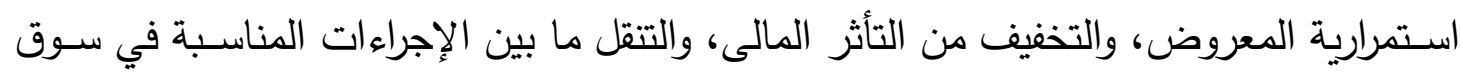
يسوده اللايقين مع انخفاض طلب المستهلكين. (World Economic Forum, 2020). ثانياً: على مستوى الحكومات: وفقاً للمعهد الدولي لبحوث السياسات الغذائية يجب معالجة سلسلة التوريد على ثلاثة مستويات، هي:

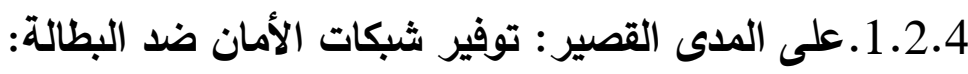

على سبيل المثال، يمكن للحكومات استخدام ما يسمى بـ "النقد مقابل العمل عash-for-work للتوظيف المؤقت للمتعطلين عن العمل في المشروعات العامة بدلاً من إعانات البطالة المباشرة.

1.2.5.وعلى المدى القصير والمتوسط: مراقبة وضبط الأسواق:

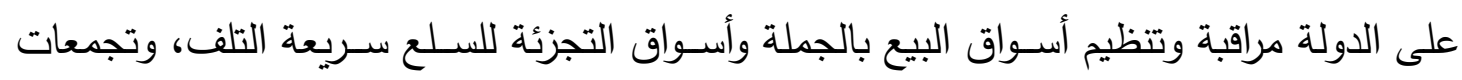
التصنيع الغذائي بشكل أكثر صرامة. 
1.2.6.في المدى الطويل: ضخ الاستثمارات طويلة الآجل:

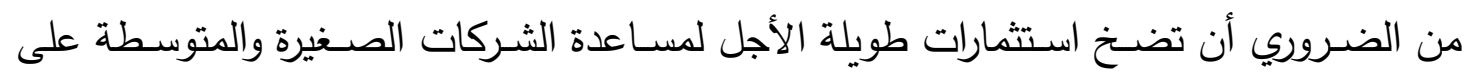
تغيير ممارسات النظافة وتحسين تصميم الموقع حفاظاً على قدرتها التنافسية. 1.3.

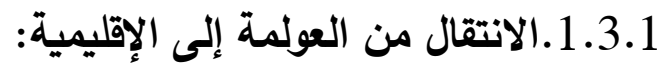
سـيحدث بعد الجائحة إعادة هيكلة ضــمة في سـلســلة التوريد باقتراب الإنتاج ومصــادره من (Craven, Singhal, \& Wilson, المستخدمين النهائيين لتأمين احتياجات الشـركات المحلية (2020) وتتطلع الثـركات في عهد ما بعد كورونا إلى توطين الإنتاج ومصــادره \&eifert )

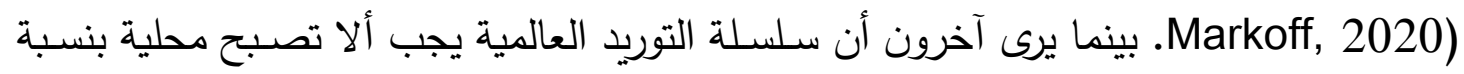
100٪، وإنما على قادة القطاعين العام والخاص أن يأخذوا في الاعتبار المخاطر التي تثــــلها سلسلة التوريد البعيدة سواء في البلدان النامية أو المتقدمة (Helper, 2020). :1.3.2."تركيز" المشروعات:

وفي المدى المتوسط، ربما تكون تلك الجائحة وسيلة من وسـائل "التركيز" والتجميع للمشـروعات

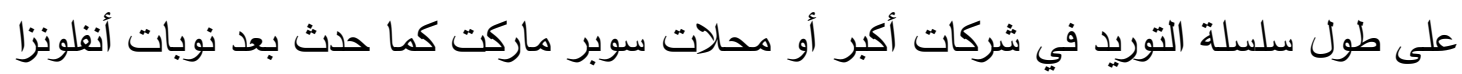

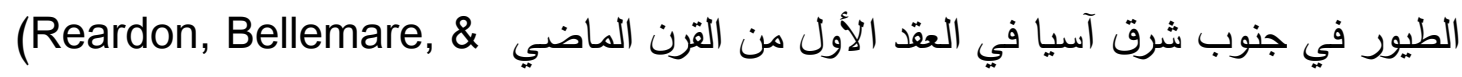
.Zilberman, 2020)

1.3.3.الاهتمام بالموردين من الارجة الأدنى من الأهمية:

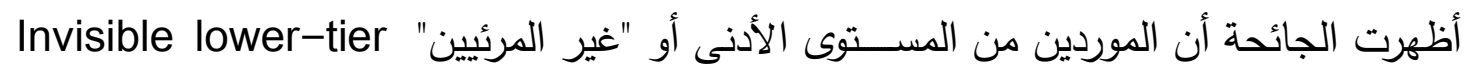
suppliers حدوث اضطرابات سريعة في جميع أنحاء السلسلة، خاصة في حال العمليات التصنيعية مرتفعة القيمة ذات سـلســلة التوريد الطويلة، والتي في السـيناريوهات السـيئة يُككن أن يؤدي غياب جزء رئيسي في العملية إلى توقف الإنتاج بالكامل (MaKenzie, 2020). 
1.1.3.4 اعتماد تنافسية الخطر بدلاً من تنافسية التكلفة:

تقليدياً، كان تحسـين تتافسـية سـلســلة القيمة العالمية يعتمد على أسـباب تتعلق بحسـن إدارة

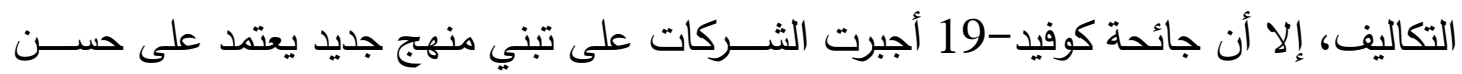

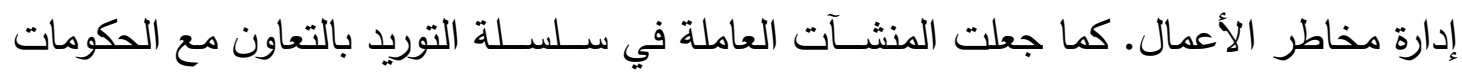
تزيد من قدرتها على التكيف مع الصــمات المسـتقبلية والاسـتجابة لها ( World Economic .2020،Forum

2.بعض مظاهر تأثير جائحة كوفيد-19 على سلسلة التوريد المحلية في مصر

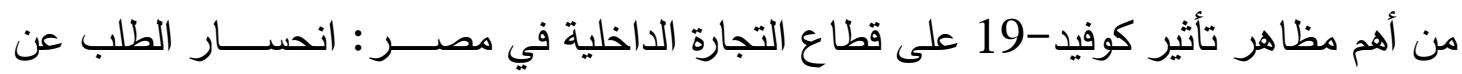
بعض القطاعات الاقتصـادية، وزيادة عدد قضـايا الغش والتلاعب في الأسـعار، وارتفاع أسـعار المستهلكين لبعض المجموعات الاستهلاكية على الرغم من الاستقرار العام في الأسعار. 2.1. تحقيق خسائر في بعض القطاعات:

تتوقع الوكالة الأمريكية للتعاون الدولي في مصـر أن قطاعات الأعمال في مصـر سـوف تتباين اســتجابتها للجائحة ما بين فائز وخاسـر . فمن القطاعات المتوقع لهم تحقيق مكاسـبـ: الزراعة،

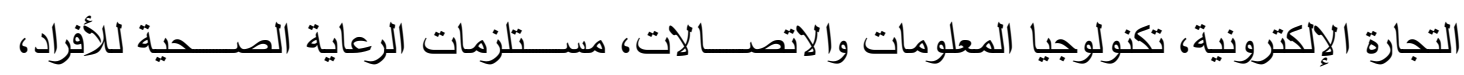
تصـــيع وتجارة الأغذية (التجزئة)، الخدمات والتوريدات الطبية. أما القطاعات التي يتوقع أن تحقق خســائر : السـياحة، النقل البحري والجوي، السـيارات، التشـيـيد والبناء، التصــنيع (غير الضــروري)، الخدمات المالية، التعليم، زيوت البترول والغاز الطبيعي (الوكالة الأمريكية للتعاون الدولي، 2020). ويتوافق ذلك مع ما كثــت عنه مسـوح المسـتهلكين في عديد من البلدان التي اجتاحها كوفيد-19، والتي بينت أن الإنفاق الأكثر كان على منتجات البقالة دون غيرها من سلع الرفاهية (Wilson, 2020).

2.2. التلاعب في الأسعار والنش التجارى:

بلغ عدد القضـايا التموينية في 5 أبريل 2020 نحو 30 ألف قضـية خلال شهرٍٍ واحدٍ. وتتوعت

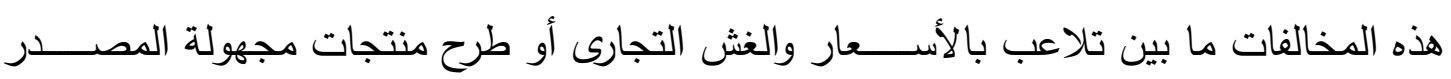
(وهبة، 2020). 
2.3. ارتفاع أسـعار المستهلكين لبعض المجموعات على الرغم من الاستقرار العام في

$$
\text { الأسعار: }
$$

يقارن الجدول رقم (1) بين معدل التضخم الثهرى (نهاية الثهر/نهاية الثهر السابق) للمجموعات

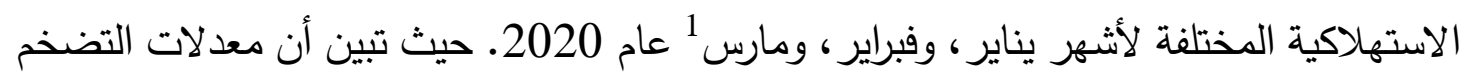

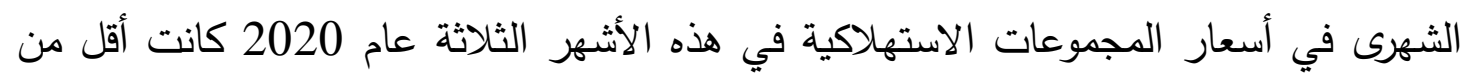

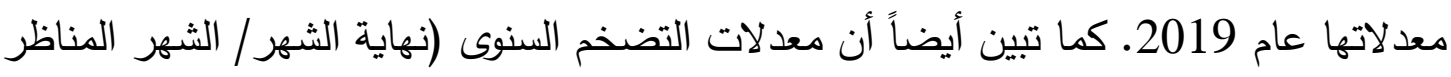

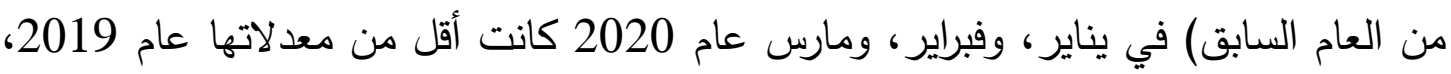

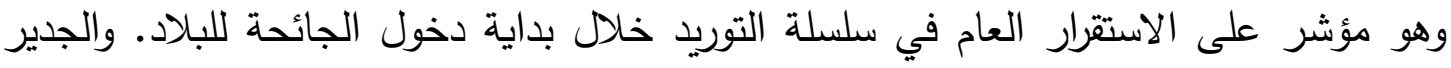

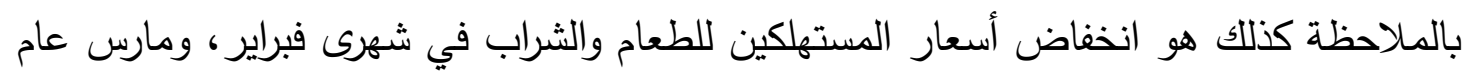

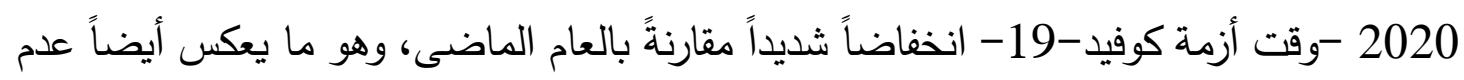

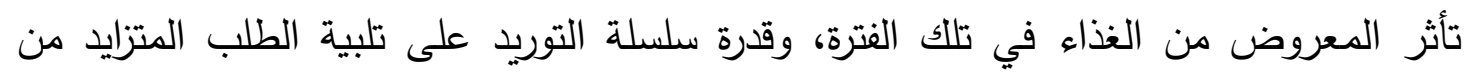

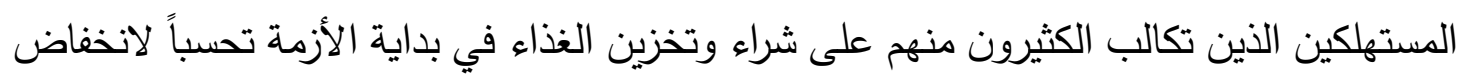

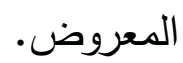

ويلاحظ من الجدول رقم (1) ارتفاع أسعار جميع المجموعات عدا الغذاء في مارس 2020 مقارنة بذات الثهر عام 2019، إلا أن أكبر المجموعات التي شهدت تضخماً في الأسعار كانت التعليم،

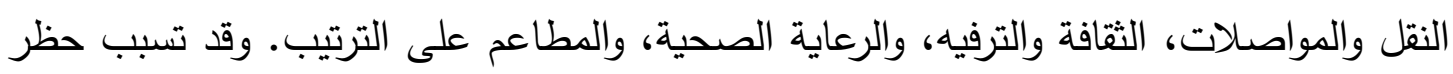

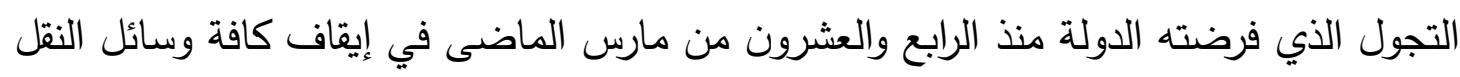

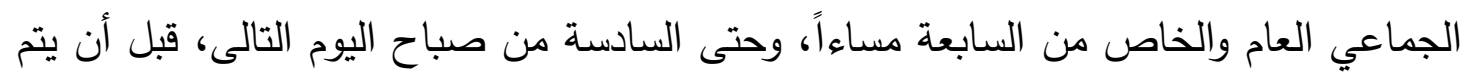

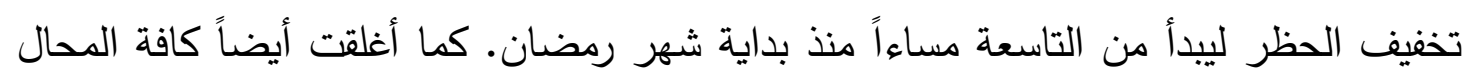
التجارية والحرفية والمراكز التجارية التي نسميها المولات ومحلات تقديم الخدمات وبيع السلع مع بلدية

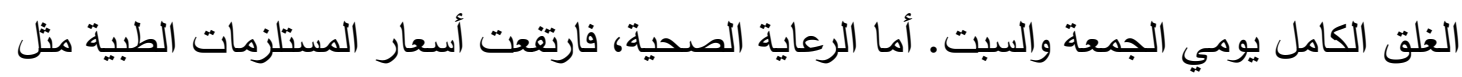

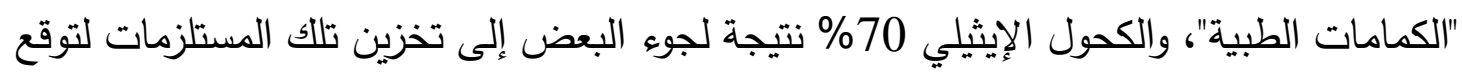

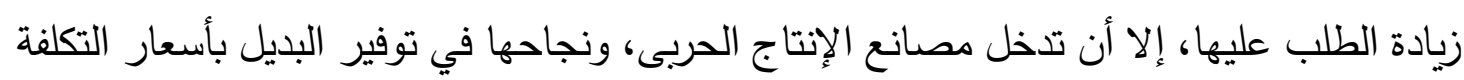

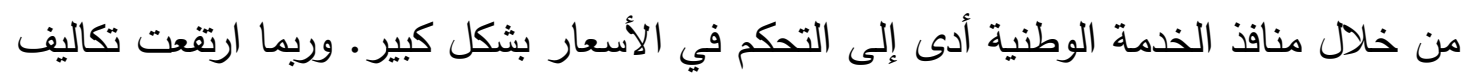

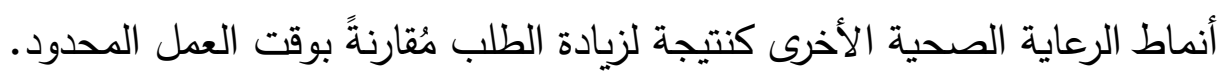

1 وهي الأثهر التي شهدت بداية أزمة كوفيد-19 في العالم أواخر ديسمبر 2019 وأوائل عام 2020، وبداية الإعلان عن أول حالة إصابة في مصر في 14 فبراير 2020 (WORLDMETERS, 2020). 
جدول 1: الأرقام القياسية لأسعار المستهلكين (حضر) خلال لثهور يناير وفبراير ومارس 2019، 2020*

\begin{tabular}{|c|c|c|c|c|c|c|}
\hline \multicolumn{2}{|c|}{ يناير } & \multicolumn{2}{|c|}{ فبراير } & \multicolumn{2}{|c|}{ 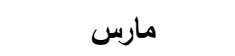 } & \multirow{2}{*}{ 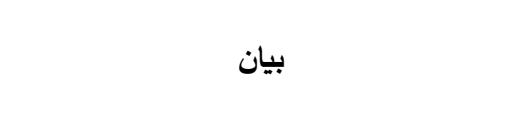 } \\
\hline 2019 & 2020 & 2019 & 2020 & 2019 & 2020 & \\
\hline 0.60 & 0.67 & 1.74 & -0.01 & 0.83 & 0.61 & معدل التضخم الثهرى \\
\hline 12.71 & 7.17 & 14.35 & 5.32 & 14.16 & 5.09 & معدل التضخم السنوى \\
\hline 12.50 & 2.62 & 15.42 & -0.89 & 15.16 & -1.74 & الطعام والمشروبات \\
\hline 10.45 & 1.44 & 10.45 & 1.44 & 10.59 & 7.49 & المشروبات الكحولية والدخان \\
\hline 7.60 & 4.03 & 9.91 & 3.70 & 9.93 & 3.61 & الملابس والأحذية \\
\hline 14.93 & 4.57 & $14 . .93$ & 4.65 & 14.92 & 4.77 & المسكن والمياه والكهرباء والنغاز والوقود \\
\hline 4.94 & 1.82 & 4.76 & 2.21 & 4.77 & 2.47 & الأثاث والتجهيزات والمعدات المنزلية والصيانة \\
\hline 5.05 & 11.66 & 5.38 & 11.48 & 5.55 & 11.64 & الرعاية الصحية \\
\hline 39.34 & 16.24 & 39.54 & 16.05 & 39.62 & 15.34 & النقل والمواصلات \\
\hline 0.03 & 2.01 & 0.03 & 2.00 & 0.03 & 4.56 & الاتصالات السلكية واللاسلكية \\
\hline 8.23 & 13.67 & 8.25 & 13.46 & 4.65 & 13.63 & الثقافة والترفيه \\
\hline 14.65 & 21.83 & 14.65 & 21.83 & 14.65 & 21.83 & 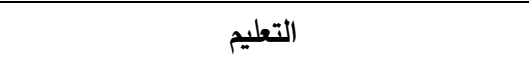 \\
\hline 11.41 & 10.27 & 12.04 & 10.62 & 12.58 & 10.63 & المطاعم والفنادق \\
\hline 7.94 & 3.70 & 8.11 & 3.69 & 7.93 & 4.36 & السلع والخدمات المتنوعة \\
\hline \multicolumn{7}{|c|}{ جموعات مستمدة من الرقم القياسى العام لحساب التضخم الأساسى } \\
\hline 23.72 & 10.27 & 32.74 & -1.08 & 32.12 & -4.13 & الخضروات والفاكهة ** \\
\hline 8.60 & -0.23 & 9.39 & -1.35 & 9.08 & -1.26 & الطعام مستبعاً منه الخضار والفاكهة \\
\hline 20.36 & 10.89 & 20.38 & 10.87 & 20.46 & 12.24 & السلع والخدمات المحدد أسعارها إداريا \\
\hline
\end{tabular}

المصدر: البنك المركزي المصري، النشرة الإحصائية الشهرية لشهور أبريل، ومارس، وفبراير 2020.

* صدرت السلسلة العاشـرة للأرقام القياسية لأسعار المستهلكين في أكتوبر 2019، واستخرجت الأوزان المستخدمة في تركيب الرقم القياسي لها من نتائج بحث الدخل والإنفاق والاستهلاك لعام 2018/2017 باتخاذ سنة 2019/2018 كفترة أساس. *** مستبعد منها البقول الجافة والفاكهة الجافة والخضروات المحفوظة والمعالجة. **** تتضمن أسعار الوقود.

\section{4. استقرار أسعار المنتجين في يناير 2020:}

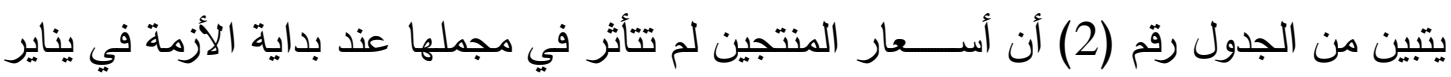

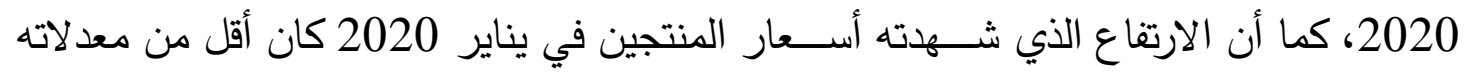

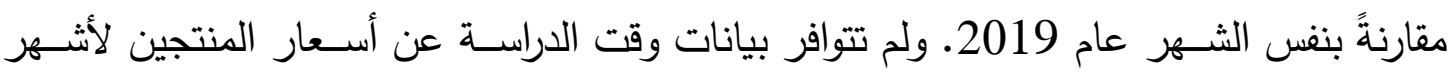

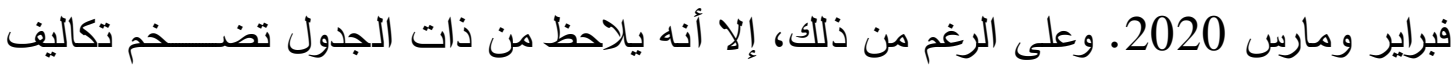

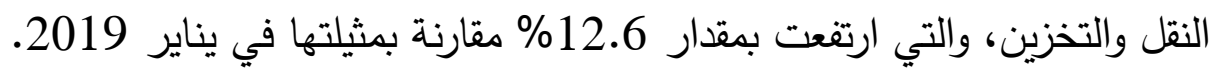


جدول 2: الأرقام القياسية لأسعار المنتجين لثهر يناير 2020*

\begin{tabular}{|c|c|c|}
\hline \multicolumn{2}{|c|}{ يناير } & \multirow{2}{*}{ بيان } \\
\hline 2019 & 2020 & \\
\hline 1.8 & -1.0 & معدل التضخم الثهرى (نهاية الثهر/ نهاية الثهر السابق) \\
\hline 7.8 & 4.0 & معدل التضخم السنوى (نهاية الثهر/ الثهر المناظر من العام السابق) \\
\hline 11.6 & -3.3 & الزراعة وصيد الأسماك \\
\hline-11.0 & 6.0 & التعدين واستغلال المحاجر \\
\hline 17.4 & 5.5 & الصناعات التحويلية الصية \\
\hline 71.1 & 20.0 & إمدادات الكهرباء والغاز والبخار وإمدادات التكييف \\
\hline 29.1 & 0.0 & أنثطة الإمداد المائى وشبكات الصرف الصحى وإدارة ومعالجة المخلفات \\
\hline 1.8 & 12.6 & 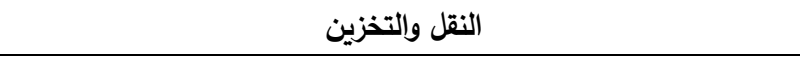 \\
\hline 9.8 & -1.8 & أنثطة خدمات الذذاء والإقامة \\
\hline 0.0 & 0.0 & أنثطة المعلومات والاتصالات \\
\hline
\end{tabular}

المصدر: البنك المركزي المصري، النثرة الإحصائية الثهرية لثهر فبراير 2020.

* أصدر الجهاز المركزى للتعبئة العامة والإحصاء سلسلة زمنية جديدة للأرقام القياسية لأسعار المنتجين باتخاذ شهر يناير 2016 كترة أساس بدلاً من سنة 2005/2004 اعتبارا من أغسطس 2017. ** مستبعد منها البقول الجافة والفاكهة الجافة والخضروات

$$
\text { المحفظة والمعالجة. *** تتضمن أسعار الوقود. }
$$

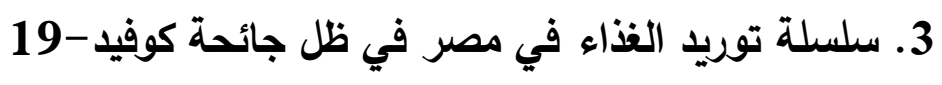
نظراً لأهمية سـلسـلة توريد الغذاء في تحقيق الأمن الغذائي بعناصـره الأربعة من توافر، وإمكانية وصــول، واســخدام، واسـتقرار ، عمدت الورقة في هذا الجزء منها إلى إلقاء الضــوء على مظاهر تأثر جانبي عرض وطلب الغذاء في مصــر، وتوقع مدى تأثر ســلســلة توريد الغذاء في حال استمرار الجائحة. 3.1

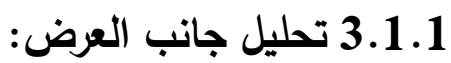

تبين للدراسـة أن عرض الغذاء لم يتأثر سـلباً حتى وقت الدراسـة بجائحة كوفيد-19. وسـاهم في ذللك توفر احتياطي استراتيجي من السلع الغذائية الأسـاسية يكفي لمدد تتراوح من أربعة إلى ستة أشــــر (ملحق رقم (1)). وعلى مســـتى القطاع الخاص تتوفر مســتلزمات الإنتاج حتى عيد الأضحى المبارك، وقد سُمح لمنشآت التصنيع الغذائي أن تعمل بالوقت الكامل على مدار اليوم. وقد أدى تواجد احتياطي حكومي كافٍ من السلع الاستراتيجية إلى استقرار السوق وقت الجائحة، وذلك جنباً إلى جنب مع الإجراءات التي تم اتخاذها لضبط الأسواق، ومنع الممارسات الاحتكارية التي أدت جميعها إلى تحقيق الوفرة، ومنع ارتفاع الأسـعار • وعلى مسـتى التوزيع، عملت جميع قنوات توصيل الغذاء إلى المستهلك بكامل قوتها سـواء التابعة لوزارة التموين والتجارة الداخلية أو 
منافذ الخذمة الوطنية التابعة للقوات المسـلحة، وتم اسـتثناء محال بيع الغذاء ـما عدا التي تعمل داخل المراكز التجارية-، وكذللك سـيارات نقل الســع الغذائية من الالتزام بمواعيد الحظر (ملاحق أرقام (1)، (3)). وعلى مسـتوى استيراد السـلع الغذائية لم تتعطل عمليات الاستيراد، وإن شـابها بعض البطيء نتيجـة تخفيض أوقـات العـل في البنوك، ولكن ظلـ الموانئ تعدل بطـاقتها الكاملة، ولم تتأثر عملياتها (ملحق رقم (7)).

وعلى مسـتوى التصـنيع الغذائي، توافرت مسـتلزمات الإنتاج سـواء المحلية أو المسـتوردة اللازمة

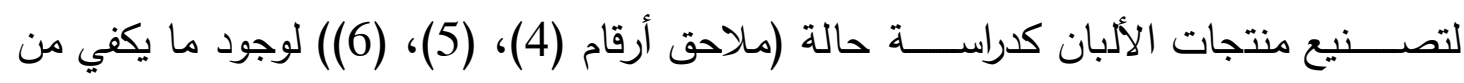

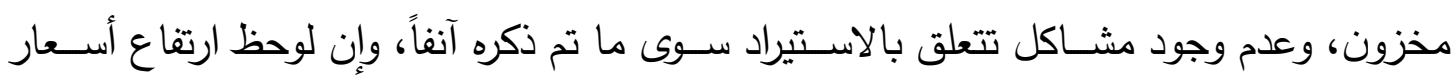
بعض مستلزمات الإنتاج المستوردة نسبياً لزيادة الطلب عليها من المصنعين وتخزينها أو التعاقد

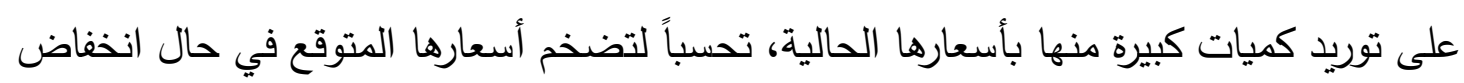
سعر الجنيه أمام الدولار نتيجة انخفاض الاحتياطي الاستراتيجي من الدولار خلال الأزمة (ملحق بـقارف

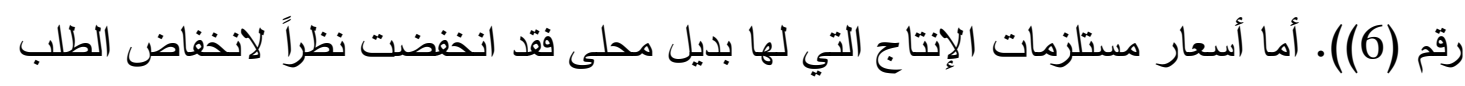
في ظل غلق عدد من المصـانع الكبرى التي ظهرت بها حالات إصـابة بكوفيد-19 في العاشـر من رمضان، والساد من أكتوبر (ملحق رقم (4)).

وقد نتج عن الجائحة، تغير في استراتيجيات الشراء للمصانع الكبرى التي أصبحت أكثر استهدافاً للبدائل المحلية لمستلزمات الإنتاج المستوردة. فعلى سبيل المثال، أصبح اللبن الخام بديلاً للألبان

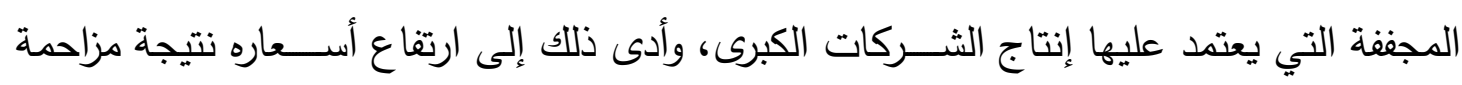
الشركات الكبرى الشركات الصغيرة والمتوسطة في الحصول عليه (ملاحق أرقام (4)، (5)). 3.1.2

في بداية الإعلان عن الإجراءات الاحترازية التي فرضتها الدولة، سارعت جموع المستهلكين إلى

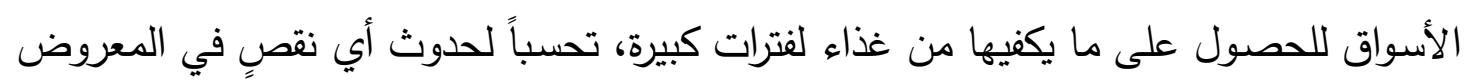
نتيجة الأزمة المستجدة، فأدى ذلك إلى زيادة مبيعات تجارة جملة وتجزئة الغذاء، والسوبر ماركت. وقد تضـافرت جهود القطاعين العام والخاص في تصـدير الثـعور بالاطمئنان للمسـتهلك بتوفير

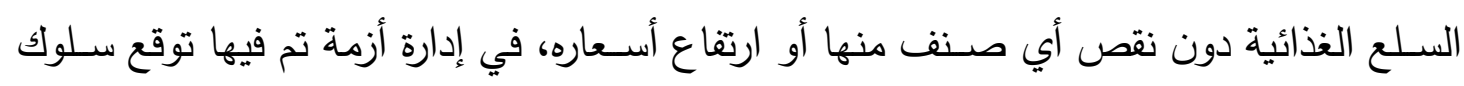


المستهلاك وتقويمه (ملاحق أرقام (1)، (3)). فسـرعان ما انتظمت الحركة في الأسـواق بمعدلات أقرب إلى ما قبل الأزمة، ثم تباطأت حركة الشراء نسبياً نظراً لأن كثير من المستهلكين قد اشتروا مستقبلاً ما يكفيهم لفتراتٍ قادمة (ملحق رقم (7)).

وعلى مستوى مصانع الأغذية، تأثرت بثدة الصادرات إلى سوق مجلس التعاون الخليجي التي تثكل 30-80\% من مبيعات الشركتين العاملتين في إنتاج الجبن محل الدراسة (ملحق رقم (4))، نظراً لأن المستوردين قاموا باستيراد كميات كبيرة قبل تطور أوضاع الجائحة عالمياً تحسباً لارتفاع

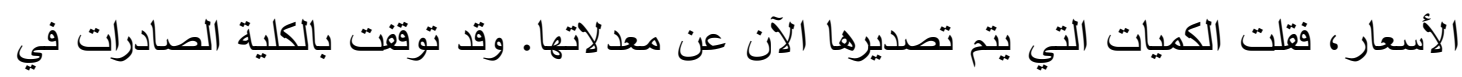
حال كان وكيل التصدير يعمل في مجال الخدمات الغذائية Food service، من توريد للفنادق والمطاعم التي تأثرت بشدة أعمالها نتيجة الجائحة. أما الصادرات إلى السوق الليبي من الألبان والعصائر فلم تتأثر (ملحق رقم (6)).

وقد أصبح السوق المحلي المصدر الأول لبيع منتجات مصانع الأغذية. إلا أن انخفاض الطلب

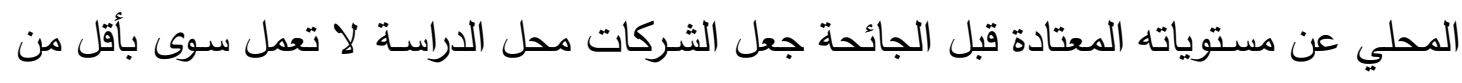
نصـف طاقتها التثــيلية (ملاحق أرقام (4)، (5)، (6)). وربما يعود تراجع الطلب المحلي على لـ

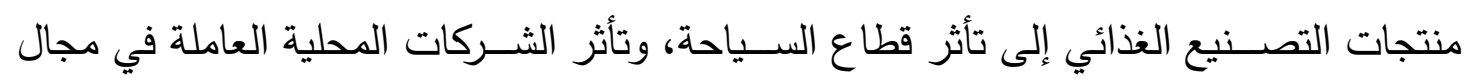
الخدمات الغذائية بشــة. ومن ناحيةٍ أخرى، انخفض الطلب المحلي خاصـةًَ في الصـعيد، نتيجة تأثر دخل العمالة الموسمية الذين فقدوا أعمالهم، والذين كانوا يُقبلون على استهـلاكل أنماط محددة تتتاسـب مع دخولهم المنخفضــة (ملحق رقم (4)). كما أن الثـركات المُنتنجة لمنتجات العصـائر

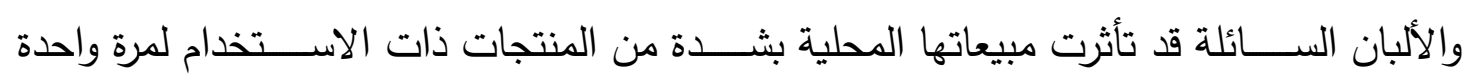
Single-serve الخطة الإنتاجية لتلك المصانع، والتي توقف البيع منها نتيجة بقاء جموع المستهلكين في المنازل، وميلهم إلى استهلاك المنتجات العائلية أو ذات الاستخدام لأكثر من مرة Multi-serve من فئة اللتر على ســبيل المثال، والتي تمثل من 50-60\% من الطاقة التشــغيلية للمصــنع. وقد زاد

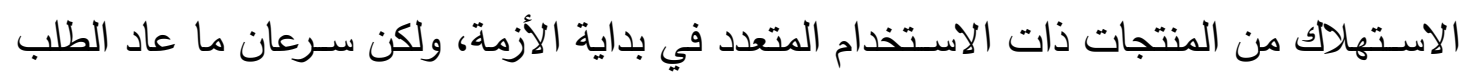

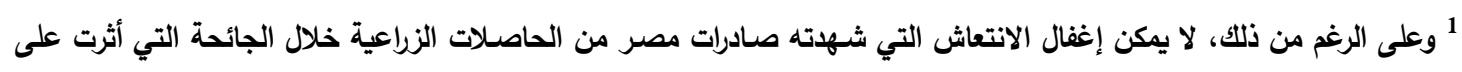
المنافسين لمصر في الأسواق الدولية مثل إسبانيا، وتركيا، وهو أمر خارج نطاق الدارسة الدانة الحالية. 
إلى معدلاته الطبيعية. وإن استمرت معاناة المصانع بالعمل بما يقرب من نصف طاقتها التشغيلية فقط، فيتوقع أن يكون عواقب ذلك تخفيض تكاليف التثـغيل بتسـريح تدريجي للعمالة (ملحق رقم

3.2 3.2.1 السيناريو المتوسط: احتواء الأزمة في سبتمبر:

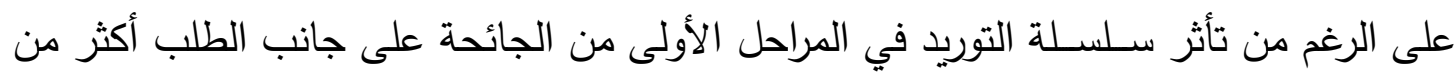
جانب العرض، إلا أنه يتوقع إذا استمرت الأزمة حتى سبتمبر أن يتأثر كلا الجانبين. حيث يعنى سنى

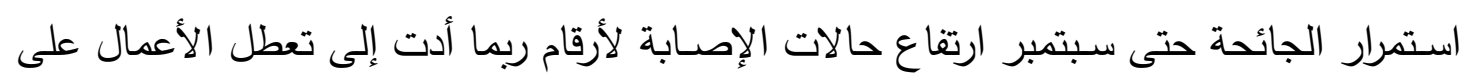
طول سلسلة التوريد. وإن كان التأثر في المعروض يمكن إدارته من خلال المخزون الاستراتيجي

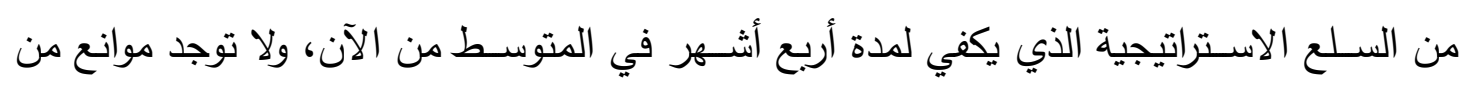
استيراد المزيد من بلدانٍ لم تتأثر تأثراً كبيراً بالجائحة.

3.2.2 السيناريو المتشائم: احتواء الأزمة في ديسمبر:

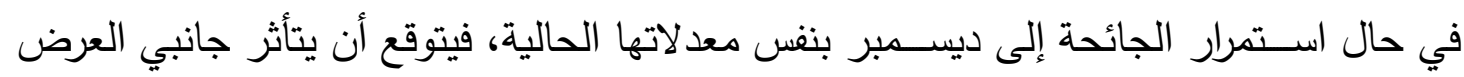
والطلب بثدة. فيعنى استمرار الجائحة إلى ذلك الوقت بنفس المعدل هو ارتفاع معدلات الإصـابة لمستويات قد تؤدى إلى تعطل كبير في الأنشطة الإنتاجية على طول سلسلة التوريد من المزرعة إلى المستهلك. كما يتوقع أن ينخفض الطلب الفعال بالمجتمع إلى درجة تُزيد من مستويات انعدام

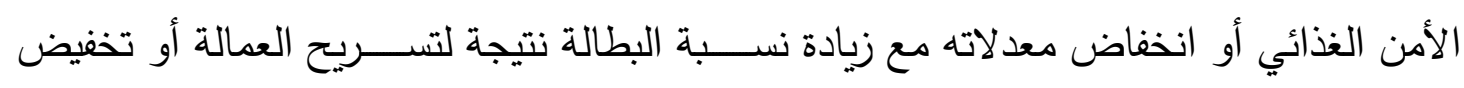
الأجور - الأن

4. كيف ستؤثر جائحة كوفيد-19 على التجارة الداخلية في مصر؟

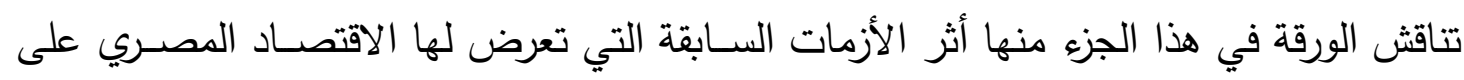

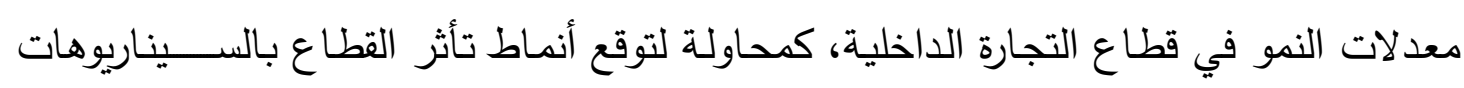
المختلفة لجائحة كوفيد-19. 


\section{1}

سبق أن تعرض الاقتصاد الدصري بقطاعاته المختلفة إلى أزمات سابقة سواء داخلية أو خارجية

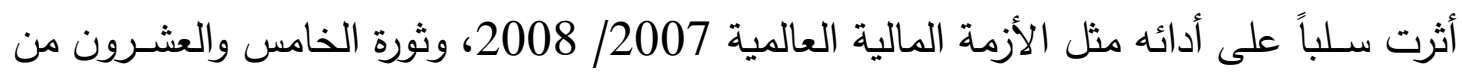
يناير 2011، بالإضـافة إلى تبعات الإصـلاح الاقتصادي وما صـاحبه من تحرير سعر الصرف في نوفمبر عام 2016. وتحاول الدراســــة في هذا الجزء منها تحليل مدى تأثر قطاع التجارة

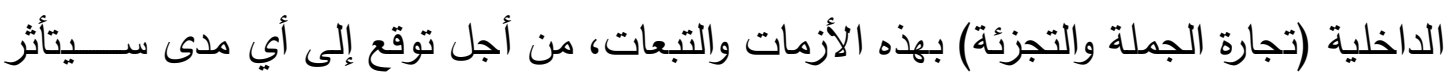
القطاع بأزمة جائحة كوفيد-19.

جدول 3: النمو في الناتج المحلي الإجمالي وتجارة الجملة والتجزئة خلال الفترة من 2008/2007 إلى 2020/2019

(\%)

\begin{tabular}{|c|c|c|c|c|c|c|}
\hline والجنارة فالجئة & النجارة في & الجمالي & الناتج النوي & الناتج النمي & النمو فالي & بيان \\
\hline 4.22 & 4.50 & 4.50 & 3.04 & 4.35 & 3.87 & المتوسط \\
\hline-11 & -0.1 & 0 & 0.2 & -0.7 & 0.3 & الحد الأدنى \\
\hline 8.2 & 10.6 & 10.5 & 7.5 & 8.3 & 7.1 & الحد الأقصى \\
\hline
\end{tabular}

المصدر: البنك المركزي المصري (2020)، النشرة الثهرية، أعداد متغرقة.

يوضــــح الجدول رقم (3) أن معدل النمو في إجمالي تجارة الجملة والتجزئة (التجارة الداخلية) قد بلغ في المتوســــ نحو 4.50\% خلال الفترة من العام المالي 2008/2007 حتى الربع الثاني من العام المالي 2020/2019. وقد بلغ معدل نمو القطاع في النصــف الأول من العام المالي 2011/2010 (قبل ثورة يناير) نحو 6.3\% متفوقاً على معدل النمو في الناتج المحلي الإجمالي في نفس الفترة الذي بلغ حوالي 5.3\% . إلا أنه بمجرد اندلاع ثورة يناير تأثرت سـلســلة التوريد بثـدة، وحدثت اضـطرابات على جانبي العرض والطلب، وانعكس ذلك في انخفاض معدل النمو في قطاع تجارة الجملة والتجزئة في متوسط الفترة من يوليو 2010 إلى مارس 2011 ليصل إلى

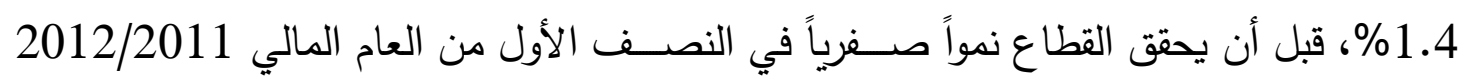

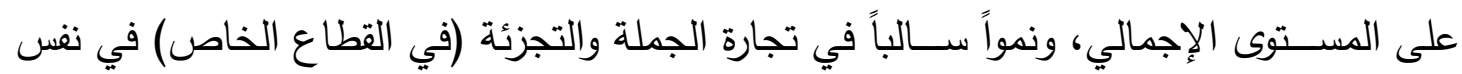
الفترة (ثــكل رقم (1)، شـكل رقم (2)). ثم بدأت مرحلة التعافي للقطاع تدريجياً، ليثـــــ نمواً 
إيجابياً بلغ نحو 1.6\% في إجمالي الفترة من يوليو 2011 إلى مارس 2012، قبل أن يتضاعف

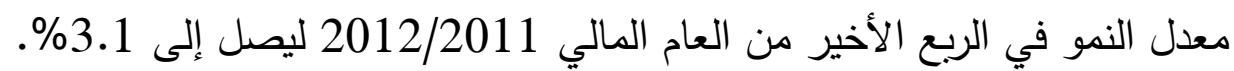
والملاحظ من الثــكل رقم (1) أن معدل النمو لإجمالي القطاع قد تأثر أيضــاً خلال فترة الأزمة المالية العالمية 2008/2007، حيث بلغ معدل النمو في قطاع تجارة الجملة والتجزئة نحو 2.2 في الربع الأخير من العام المالي 2008/2007. كما أوضـح الثـكل رقم (3) أن تجارة الجملة والتجزئة (في القطاع العام) قد حققت نمواً سالباً بلغ نحو 11\% في ذات الفترة. ولم يشهـ

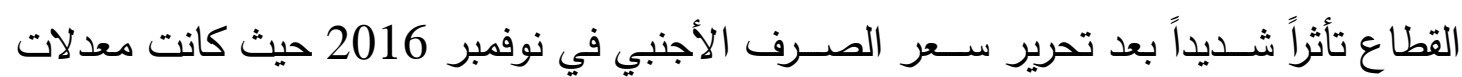
النمو حول متوسطاتها خلال فترة الدراسة.

شكل (' ): النمو في إجمالى تجارة الجملة والتجزئة من 2007 إلى 2019 (سبة مئوية)

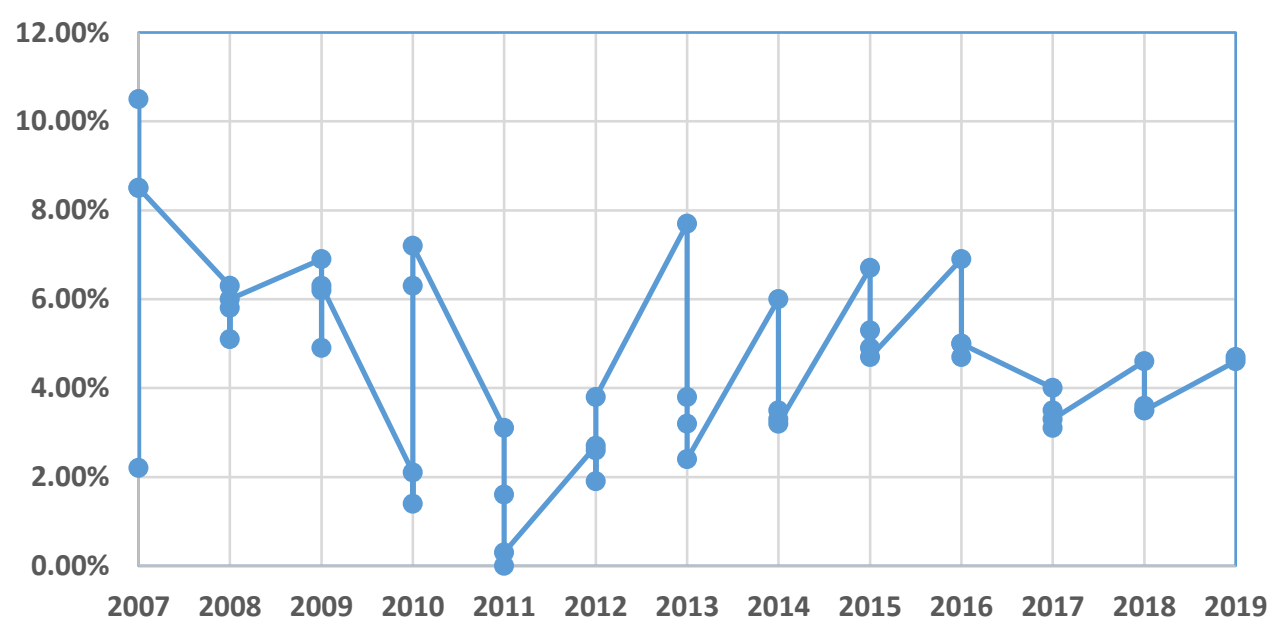

المصدر: البنك المركزي المصري (2020)، النشرة الثهرية، أعداد متغرقة.

شكل (ץ): النمو في تجارة الجملة والتجزئة (خاص) من 2007 إلى 2019 (سبة منوية)

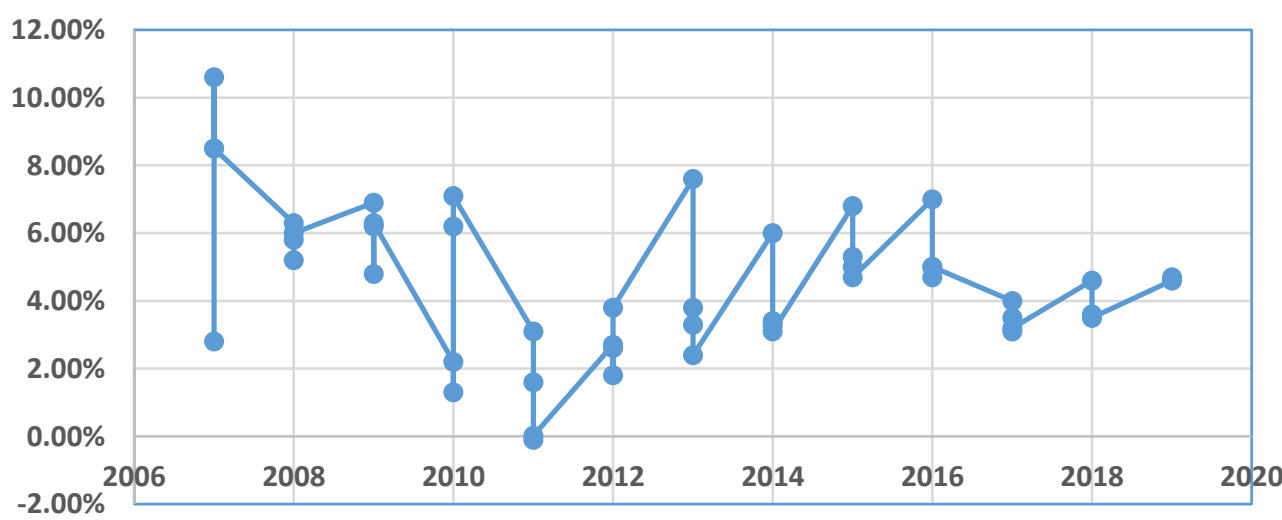

المصدر: البنك المركزي المصري (2020)، النشرة الثهرية، أعداد متفرقة. 
شكل ("): النمو في تجارة الجملة والتجزئة (قطاع عام) من 2007 إلى 2019 (سبة منوية)

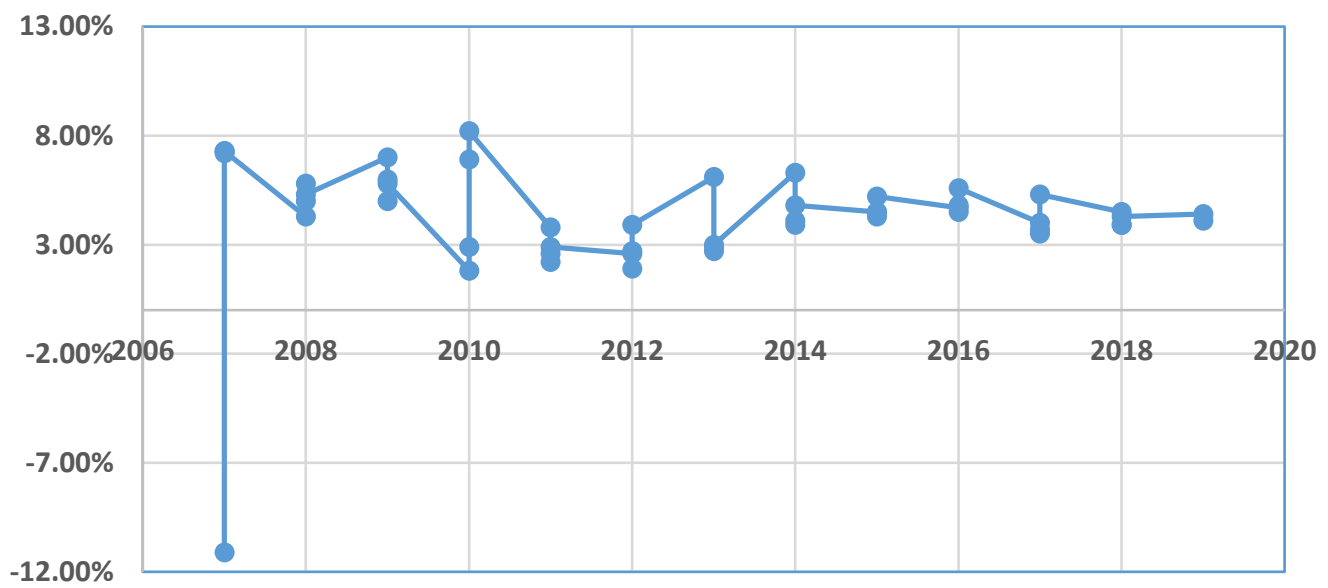

المصدر: البنك المركزي المصري (2020)، النشرة الثهرية، أعداد متفرقة.

ولا شـك أن جائحة كوفيد-19 في مراحلها الأولى وحتى وقت الدراسـة لم تتسبب في تعطل كامل

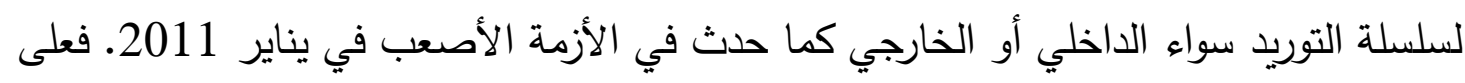
الرغم من الإجراءات الاحترازية، وقرارات فرض حظر التجول إلا أن حركة التوريد مازالت مستمرة،

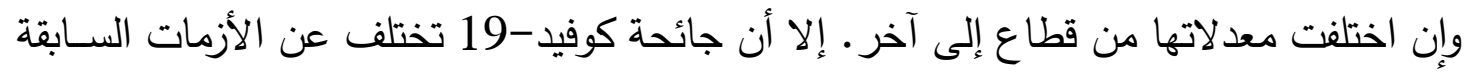

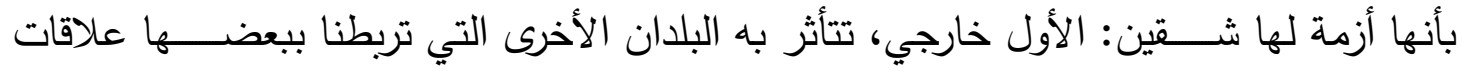

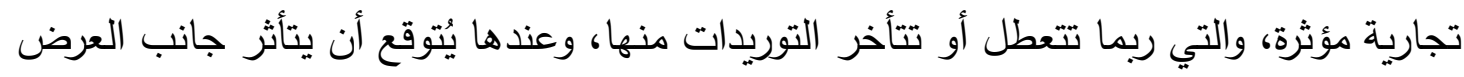

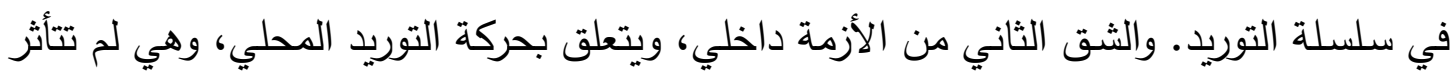

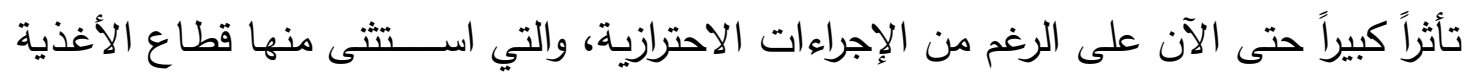

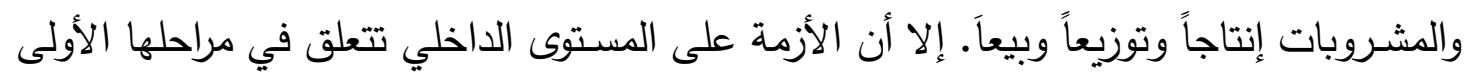

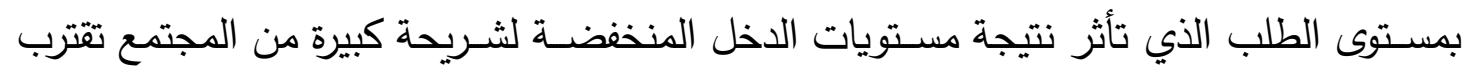
من الثلث وفقاً لما كثف عنه بحث الدخل والإنفاق لعام 2018/2017. وقد أدت الدعوات للبقاء في المنزل في بداية الأزمة من أجل تقليل فرص انتقال الجائحة إلى تأثر شريحة كبيرة من العمالة غير المنتظمة، والموسمية الذين فقدوا أعمالهم، وتأثرت دخولهم.

يفترض هذا السـيناريو انحسـار الجائحة في نهاية العام المالي 2020/2019 أي بعد ما يقرب من ثلاثة أثــهر من بداية مُجابهة الأزمة فرض الإجراءات الاحترازية. ويعنى ذلك عودة النشـاط 
إلى سـلسـة التوريد، والتعافي السـريع. وعندها تكون استجابة قطاع تجارة الجملة والتجزئة تقترب منها في حال أزمة سعر الصرف في نوفمبر 2016، وعندها يتوقع أن يبلغ معدل النمو الإجمالي في القطاع نحو 3.3\%. ويدعم ذللك الانخفاض النسـبـي المتوقع في معدلات النمو لقطاع تجارة الجملة والتجزئة ما شـــــته عمليات التســــيل التجاري من تعطل أثناء قرارات تعطيل الأعمال الحكومية ضمن الإجراءات الاحترازية التي فرضتها الدولة لإدارة الأزمة (ملحق رقم (2)).

4.2.2 في حال اسـتمرار الجائحة إلى سـبتمبر ، فيتوقع أن تكون اسـتجابة القطاع تقترب منها في حالة الأزمة المالية العالمية 2008/2007، والتي بلغ فيها معدل نمو القطاع 2.2\%، وحققت تجارة الجملة والتجزئة في القطاع العام نمو سلبي.

4.2.3 في حال اســتمرار الجائحة إلى ديسـمبر ، يُتوقع حدوث تعطل كبير في سـلسـلـة التوريد المحلية والدولية، وانخفاض شديد في مستويات الطلب. ومن الأرجح في هذه الحالة أن يستجيب القطاع

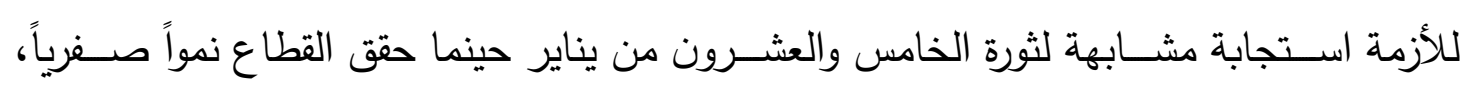
وحقتت تجارة الجملة والتجزئة في القطاع الخاص نمواً سالباً.

5. التدخلات الحالية والمقترحة لدفع النمو في التجارة الداخلية في مصر في ظل ما توصلت إليه الدراسـة من نتائج في أجزائها السـابقة، تحاول الدراسـة في الجزء الأخير منها الوقوف على أهم التخخلات ذات الصلة بسلسلة التوريد التي تتذذها الدولة المصرية لمعالجة

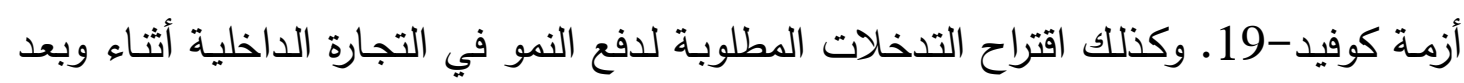

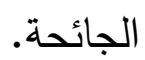

5.1 التدخلات الحالية لدفع النمو في التجارة الداخلية أثناء الجائحة:

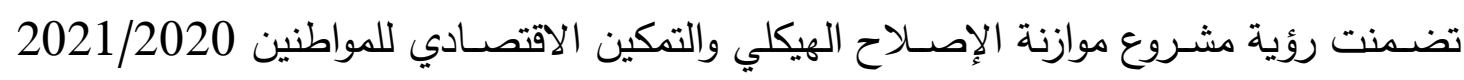

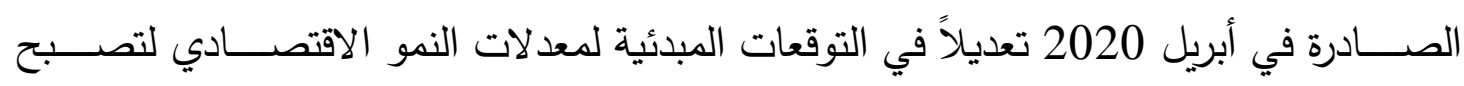

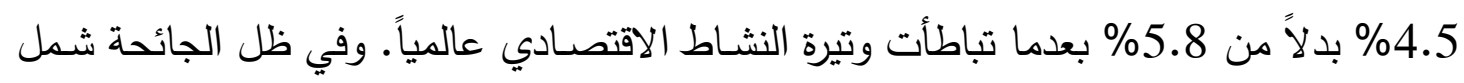


مشروع الموازنة تعزيزاً في المخصصات المالية للإنفاق على الصحة والبحث العلمي بنسبة زيادة بلغت نحو 45\%، 14.1\% على الترتيب مقارنة بالعام المالي الحالي (وزارة المالية، 2020).

وقد تضــنت الموازنة مخصـصـات مالية لتمويل حزمة إجراءات بمبلغ 100 مليار جنيه تخص التكليف الرئاســي للحكومة المصـرية لتنفيذ الخطة الثـاملة لمواجهة جائحة فيروس كوفيد-19، ومن أهم القرارات ذات الصــلة بسـلســلة التوريد المحلية والقطاعات الإنتاجية: خفض أســعار الكهرباء للصناعة للجهد الفائق والعالي والمتوسط بقيمة عشرة قروش/ كيلووات ليبلغ سعر الكيلو وات 1.08 جنيهاً لمدة 3-5 سنوات. كما تضمن مشروع الموازنة عدداً من السياسات التوسعية التي تسـتهدف في الأسـاس حث الطلب خلال الأزمة الحالية، منها: رفع حد الإعفاء الضـــيبي على الثـــرائح المختلفة للدخول، وخفض مدفوعات الفوائد بنســبة 0.6\%، زيادة الاســتثمارات

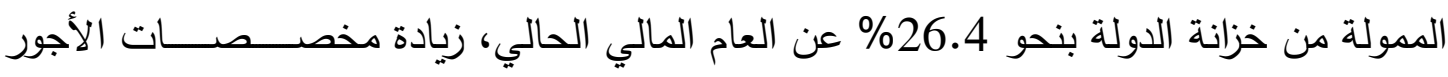
بنسبة 11.3\% عن موازنة العام السابق (وزارة المالية، 2020).

\section{2 التدخلات المقترحة لافع النمو في التجارة الداخلية أثناء الجائحة:}

ضـرورة عودة الحياة الاقتصـادية المشروط باتخاذ كافة الإجراءات الكفيلة بجعل منحنى الإصـابة بالجائحة يتوقف عن الارتفاع.

فاسـتمرار تطبيق الحظر سـوف يترتب عنه عواقب اقتصــادية جسـيمة على مســتوى الوحدات المُنتجة في سـلسـلة التوريد نتيجة انحســار مسـتويات الطلب، وانخفاض معدلات التدفق النقدي لانخفاض المبيعات، وهو الأمر الذي إن اســتمر ســـؤدي إلى تســريح تدريجي للعمالة لتقليل

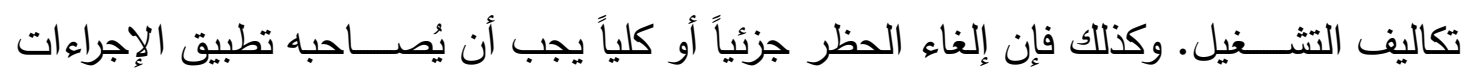
الصــية من ارتداء مهمات الوقاية، واســخذام المطهرات على مسـتوى الأفراد، وزيادة اختبارات الكثف المبكر بين مخالطي الحالات المُسجلة للحد من زيادة الأعداد، وإلا فإن حالات الإصـابة سوف تتزايد بمعدلات من المكن أن تؤدي إلى تعطل كبير للأنثطة على جميع مستويات سلسلة التوريد.

ولتحقيق هذه المُعادلة في ظل الظروف الاقتصـادية الحالية يستلزم الأمر تضـافر جهود العاملين في ســلســلة التوريد مع الحكومة من أجل زيادة الإنفاق على توفير مهمات الوقاية لجمهور 
المواطنين بالكميات والأسعار المناسبة، وإجراء إجراءات الكثف عن المشتبه في إصابتهم. ومن هنا يُقترح أن تسـاهم الثركات في سلسلة التوريد كجزء من مسؤولياتهم المجتمعية مع الدولة في تمويل هذا الإنفاق الضروري للخروج من الأزمة.

كما يُقترح:

تبني برامج صارمة لتحسين الممارسات الصحية في المؤسسات الخدمية وفي القطاعين العام والخاص، للحد من انتثار الجائحة داخل تلك المؤسسات.

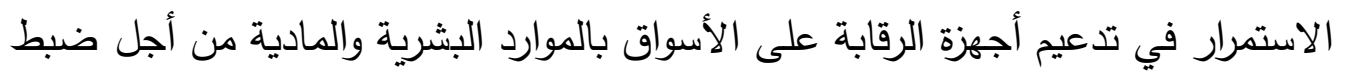

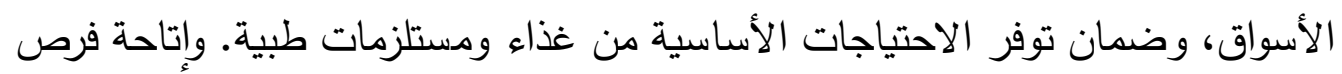
عمل مؤقتة للشباب في أجهزة الرقابة على الأسواق مقابل أجر "خدمة عامة".

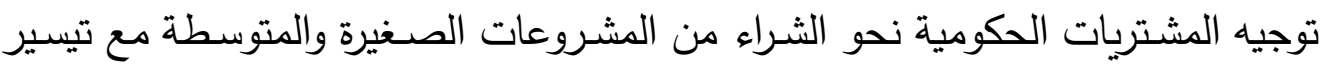
التحويلات المالية من أجل حث الطلب على منتجاتهم.

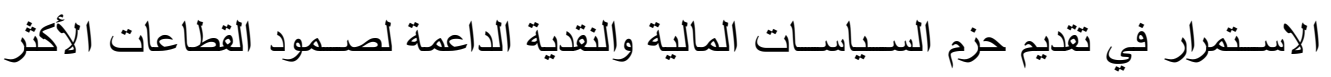

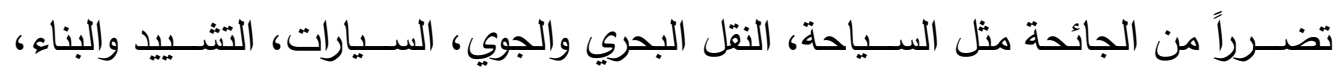

التصنيع (غير الضروري)، الخدمات المالية، التعليم، زيوت البترول والغاز الطبيعي. تفعيل دور جهاز تتمية المشروعات الصغيرة والمتوسطة من خلال طرح فرص مشروعات جديدة زراعية وصـناعية وخدمية على طول سـلسـلة التوريد في ريف الصـعيد، والقرى الأكثر فقراً. يُقترح تبني مبادرة لتعظيم الاستفادة من الموارد على مستوى الهيئات والمصالح الحكومية والثــركات في القطاع الإنتاجي العام والخاص ذات الأنثـطة المشــتركة من أجل زيادة التسيق فيما بينها لتعظيم العائد من استخدام مواردهم البشرية والمادية. هالاستمرار في تدعيم شبكات الأمان ضد البطالة خاصة في العمالة الموسمية.

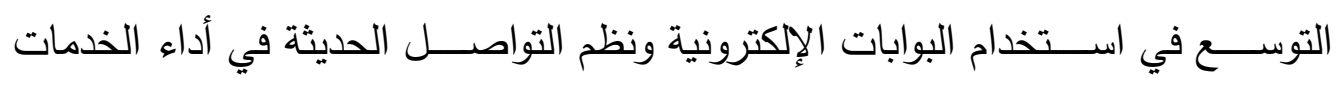
الحكومية المختلفة.

5.3 التخلات المقترحة لدفع النمو في التجارة الداخلية بعد الجائحة:

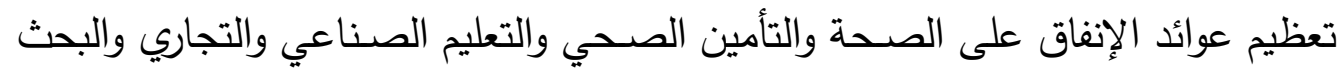
العلمي والابتكار ، ولا شـك أن ذلك من شـأنه دفع النمو في جميع القطاعات الاقتصـادية 
بالدولة عامةً، وخلال سلسلة التوريد المحلية خاصةً من خلال توفير والحفاظ على الموارد البشرية المؤهلة، وتعظيم الاستفادة من الموارد المادية.

الانتهاء من إتاحة جميع الخدمات الحكومية من خلال المنصات الإلكترونية.

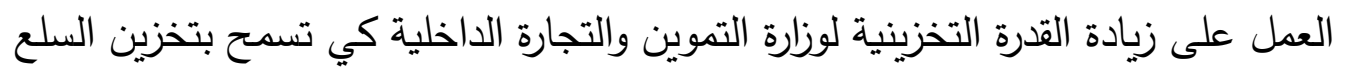
الاستراتيجية لمدة من 6-9 شهور . تتويع مصادر توريد السلع الاستراتيجية المستوردة بحيث تشمل بلدان متعددة من قاراتٍ مختلفة، مع تبني استراتيجية لإحلال الواردات من السلع الاستراتيجية.

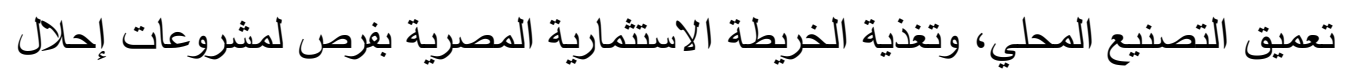

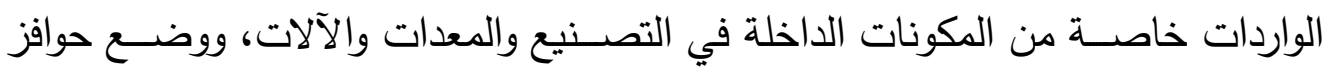
استثمارية مناسبة لجذب الاستثمارات المحلية والأجنبية لتنفيذ تلك المشروعات. زيادة الاستثمارات المنفذة في قطاع تجارة الجملة والتجزئة من أجل تحسين أداء الأسواق، وتطوير سلسلة التوريد. خاتمة: - مات

خلصت الورقة إلى أن معدلات النمو في قطاع التجارة الداخلية في مصر ستتأثر بجائحة كوفيد-

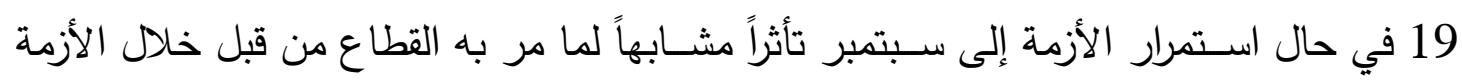
المالية العالمية 2008/2007 عندما انخفض معدل النمو الإجمالي في القطاع إلى 2.2\%

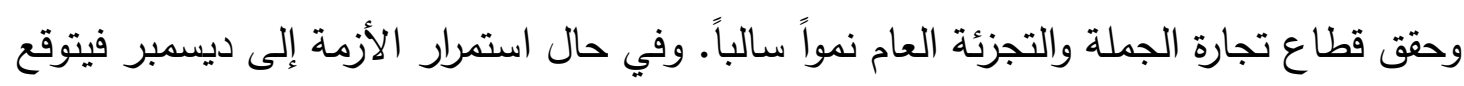

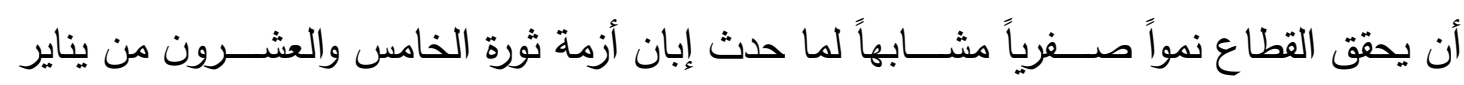

وعلى مسـتوى ســــلة التوريد المحلية للغذاء، كان جانب الطلب هو الأكثر تأثراً بجائحة كوفيد19 أكثر من جانب العرض حتى وقت الدراسة. وفي حال استمرار الأزمة إلى سبتمبر فيتوقع أن يتأثر كلا الجانبين في حال ازدياد أعداد الإصـابة في المؤسـسـات العاملة في سـلســلة التوريد المحلية للغذاء. وفي حال اســـمرار الجائحة إلى ديســمبر فيتوقع أن يحدث تعطلاً كبيراً في لإني

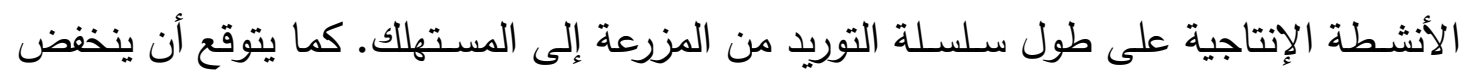

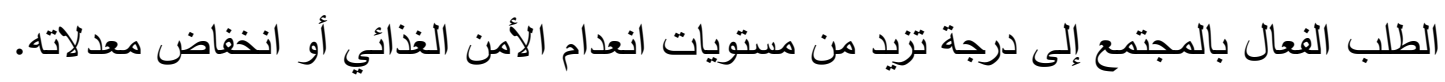


ومن التدخلات الضـرورية أثناء الأزمة: العمل على منع تطور أعداد الإصـابة، والإنفاق من أجل الحد من تفشـي الجائحة خلال سـلسـلة التوريد بتضـافر جهود القطاع الخاص مع الدولة كثـرط لتخفيف الإجراءات الاحترازية، وتبني برامج لتحسين الممارسات الصحية في المؤسسات الخدمية والإنتاجية، مع تثـديد الرقابة على الأســواق لضــــان توفر الغذاء والمسـتلزمات الطبية، وزيادة

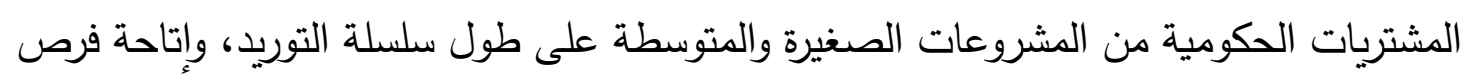

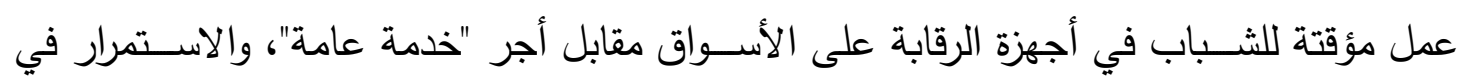

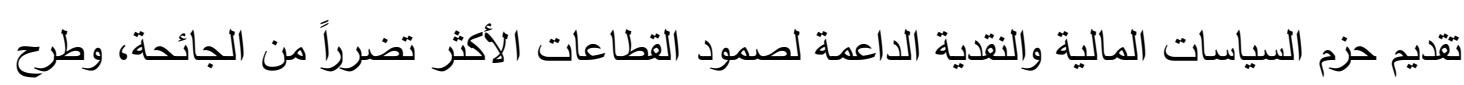
فرص مشـروعات جديدة زراعية وصـناعية وخدمية على طول سـسـلة التوريد في ريف الصـيد، والتتسيق بين المؤسسات الخدمية والإنتاجية ذات الأنشطة المشتركة لتعظيم الاستفادة من مواردهم البشرية والمادية، والتوسع في استخدام البوابات الإلكترونية في تقديم الخدمات الحكومية.

ومن التدخلات الضرورية بعد الأزمة: تعظيم عوائد الإنفاق على الصحة والتأمين الصحي والتعليم الصـناعي والتجاري والبحث العلمي والابتكار لجعل البيئة الاقتصـادية والاجتماعية أكثر صـوداً في مجابهة مثل تلك الأزمات، وزيادة الســـعة التخزينية لوزارة التموين والتجارة الداخلية، وتتويع

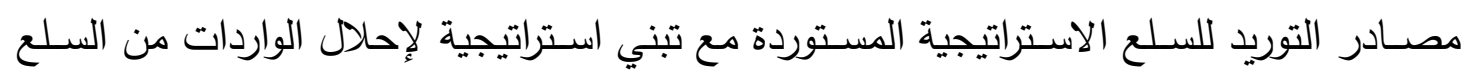
الاستراتيجية، وتعميق التصنيع المحلي خاصة للمكونات الداخلة في التصنيع المستوردة والمعدات والآلات، وزيادة الاستثمارات المنفذة لتطوير سلسلة التوريد المحلية. إن الإنفاق على منع تفشـي الجائحة داخل المجتمع وقطاعاته الاقتصـادية ومنها سـلسـلة التوريد المحلية هو الخيار الأقل تكلفة. 


\section{المراجع}

\section{أولاً: مراجع باللفة العربية}

\section{ثانياً: مراجع باللغة الأجنبية}

- Bellemare, M. F. (2015). Rising Food Prices, Food Price Volatility, and Social Unrest. American Journal of Agricultural Economics, 97(1), 1-21.

- Boyd, J. (2020). COVID-19 Survey: Impacts On Global Supply Chains. Arizona: Institute for Supply Management.

- Caldwell, J. (2020, April 16). How Covid-19 is impacting various points in the US food \& ag supply chain. Retrieved from AgFunder Network Partners: https://agfundernews.com/how-covid-19-is-impacting-various-points-in-the-food-agsupply-chain.html

- Craven, M., Singhal, S., \& Wilson, M. (2020). COVID-19: Briefing note, April 13, 2020. New York: McKinsey \& Company.

- Helper, S. (2020, April 22). How COVID-19 makes the case for 'high-road' supply chains. Retrieved from SUPPLYCHAINDIVE: https://www.supplychaindive.com/news/coronavirusmakes-the-case-for-high-road-supply-chains/576575/

- Keogh, J. (2020). COVID-19: Rules of the game must be changed to ensure the supply of food. Available at: https://www.researchgate.net/publication/340065888 COVID19 Rules of the game must be changed to ensure the supply of food.

- MaKenzie, B. (2020). Beyond COVID-19: Supply Chain Resilience Holds Key to Recovery. Oxford: Oxford Economics. 
- Nelson, R. (2020). COVID-19 disrupts vaccine delivery. The Lancet Infectious Diseases. doi:https://doi.org/10.1016/S1473-3099(20)30304-2

- Reardon, T., Bellemare, M. F., \& Zilberman, D. (2020, April 2). How COVID-19 may disrupt food supply chains in developing countries. Retrieved from International Food Policy research institute: https://www.ifpri.org/blog/how-covid-19-may-disrupt-food-supplychains-developing-countries

- Reardon, T., Echeverria, R., Berdegué, J., Minten, B., Liverpool-Tasie, S., Tschirley, D., \& Zilberman, D. (2019). Rapid transformation of food systems in developing regions: Highlighting the role of agricultural research \& innovations. Agricultural Systems, 47-59.

- Rowan, N. J., \& Laffey, J. G. (2020). Challenges and solutions for addressing critical shortage of supply chain for personal and protective equipment (PPE) arising from Coronavirus disease (COVID19) pandemic - Case study from the Republic of Ireland. Science of the Total Environment.

- Schoenfeldt, T. I. (2008). A Practical Application of Supply Chain Management Principles. Milwaukee: American Society of Quality.

- Seifert, R., \& Markoff, R. (2020). Digesting the Shocks: How Supply Chains Are Adapting to the Covid-19 Lockdowns. Lausanne: International Institute for Management Development.

- The Global Fund. (2020, April 20). COVID-19 Impact on Health Product Supply: Assessment and Recommendations. Retrieved from the Global Fund: https://www.theglobalfund.org/en/covid-19/health-product-supply/

- WHO), W. H. (2020). Coronavirus disease 2019 (COVID-19): WHO Thailand Situation Report- 23 March 2020. Geneva: WHO.

- Wilson, G. (2020, April 3). COVID-19: five priorities for retail supply chain. Retrieved from Digital Supply Chain: https://www.supplychaindigital.com/supply-chainmanagement/covid-19-five-priorities-retail-supply-chain

- World Economic Forum. (2020). How to rebound stronger from COVID-19: Resilience in manufacturing and supply systems. Geneva: World Economic Forum. Retrieved from http://www3.weforum.org/docs/WEF GVC the impact of COVID 19 Report.pdf

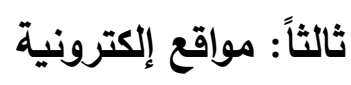

http://Www.itda.gov.eg -

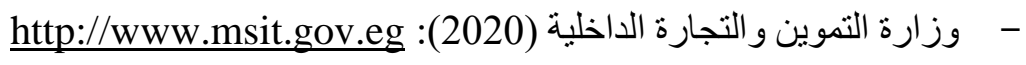
https://www.worldometers.info/ :(2020) WORLDMETERS - 


\section{الملاحق}

ملحق (1): سياسات وزارة التموين والتجارة الداخلية لإدارة سلسلة التوريد خلال الجائحة ملحق (2): مدى تأثر عمليات التسجيل التجارى ملحق (3): دور مديريات التموين والتجارة الداخلية في ضبط الأسواق ملحق (4): تحليل جانبي العرض والطلب في المصانع كبيرة السعة لإنتاج الجبن ملحق (5): تحليل جانبي العرض والطلب في المشروعات الصغيرة المنتجة للجبن ملحق (6): تحليل جانبي العرض والطلب في المصانع كبيرة السعة لإنتاج الألبان والعصائر ملحق (7) استقرار سلسلة توريد الغذاء لتجار الجملة والتجزئة 


\section{ملحق (1)}

\section{سياسات وزارة التموين والتجارة الاخلية لإدارة سلسلة التوريد خلال الجائحة}

(مقابلة مع معاون وزير التموين والتجارة الداخلية لشئون التموين ومنافذ تجارة التجزئة)

$$
13 \text { مايو } 2020
$$

فرضت وزارة التموين والتجارة الداخلية حالة استتفار رقابي وتمويني مع بداية أعمال اللجنة العليا لإدارة أزمة فيروس كورونا التي يترأسـها رئيس مجلس الوزراء، وبعضــــية وزير التموين والتجارة

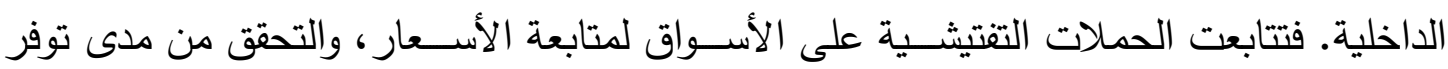
مسـتلزمات الوقاية الطبية، واتخاذ الإجراءات الرادعة للاحتكار أو حجب المنتجات غير المطابقة عن التداول التي تتضـــن مصــادرة المنتجات، وســب الرخصــة التجارية، ومضــاعفة الغرامة المالية، وتحويل جميع محاضر المخالفات إلى نيابة أمن الدولة العليا طوارئ.

وتم العمل على توفير احتياطي آمن للســلع الاســتراتيجية لا يقل عن ثلاثة أثـــر ، في ظل ما وفرته الحكومـة من مبلغ 1.8 مليار دولار عـام 2016 لوزارة التموين والتجارة الداخلية لهذا الغرض. فلا يقل الاحتياطي الاستراتيجي من زيوت الطعام على سبيل المثال عن خمسـة أشهر ، ومن القهح عن أربعة أشهر ، ومن الأرز عن أربعة أشهر أيضاً والذي سيبدأ موسم التوريد المحلي له في 15 سبتمبر القادم. وقد استتبلت صـوامع الوزارة 2.3 مليون طن قمح من المزارعين حتى 13 مايو، ومتوقع أن يمتد التوريد إلى 15 يوليو من العام الجاري ليصـــلـل إجمالي المخزون المحلي إلى 3.6 مليون طن. وقد ساعد على سرعة معدلات "تشوين" القدح عمل الديريات على فترتين صباحية ومسائية، ودفع المستحقات للمزارعين خلال 48 ساعة من الاستلام. كما عملت الوزارة على توفير احتياطي اســتراتيجي من اللحوم البرازيلي والســــوداني ومن اللحوم الدجمدة والدواجن تكفي لمدة 6 شهور • وقد أدى الاحتياطي الحكومي من السلع الاستراتيجية إلى استقرار السوق وقت الجائحة، وتحقيق الوفرة.

وعقد الوزير اجتماعات مع ممثلين لسلسلة التوريد المحلية، للوقوف على استعداداتهم لرمضـان، وتم التحقق من أن خامات ومسـتلزمات الإنتاج متوفرة، وتكفي حتى عيد الأضــى المبارك. وتم

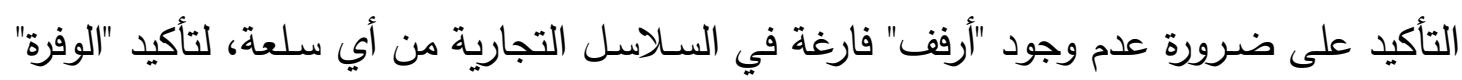
للمستهلكين، والحد من ميل المستهلك "الغريزي" إلى التخزين في وقت الأزمة، وذلك إرساءً لمبدأ 
"توفير السلع مقدمٌ على سعرها"، فالوفرة والإتاحة هما عنصران أسـاسيان لاستقرار الأسواق. كما تم العمل على ضمان سهولة حركة التوزيع على طول سلسلة التوريد من خلال انتظام العمل في لتحني

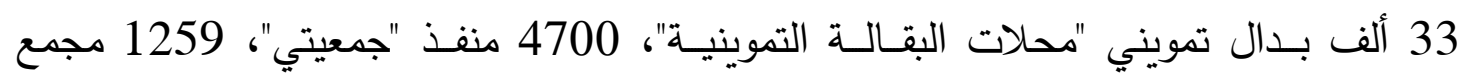
اســتهلاكي، بالإضــافة إلى أكثر من 600 مقر وفرع للســلســلة التجارية. وتم انتظام صــرف الحصــص التموينية لنحو 64 مليون مواطن مســـفيد من الدعم التمويني (22 مليون بطاقة تموين). وأنتظم 30 ألف مخبز لإنتاج 250-270 مليون رغيف لنحو 72 مليون مواطن داخل ملاطي

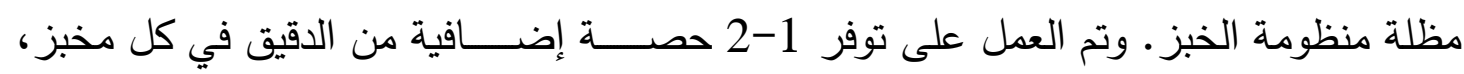
وكنلك وجود احتياطي 5 أيام في كل مطدن للدقيق. وقد سـاعد في تحقيق الوفرة للمســتهلكين اســثناء جمع محال البقالة والســوبر ماركت والطيور والجزارة من تطبيق مواعيد الحظر • كما سُمح للمطاعم بتقديم خدمة التوصيل للمنازل طوال اليوم.

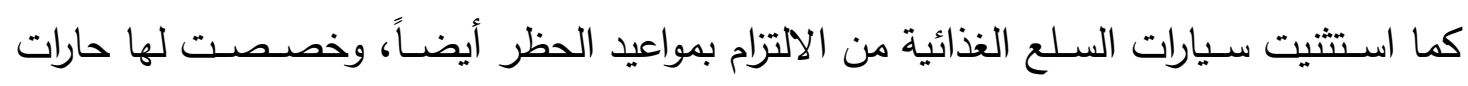
مرورية في الكمائن. وقد ســــاهم ذلك في تحقيق انســـيابية التوريد، ووفرة في المعروض. كما أصبحت مكاتب التموين الإكترونية، ويمكن من خلالها للمواطن استخراج بطاقة تموين جديدة أو بدل فاقد أو تالف.

وتم التعاون مع مشـروع تحيا مصــر ، ومشــروعات شــباب الخريجين في توفير المنافذ الثابتة والمتحركة المرتكزة في عواصم الدحافظات لضمان التدفق السلعي المباشر إلى المستهلكين. كما تم تكليف مديريات التموين والتجارة الداخلية بالدحافظات بالتعاون مع الوزير المحافظ المختص في تحديد جميع الاحتياجات التموينية لكل محافظة. وتحديد الأماكن التي تم عزلها بسبب انتشار الجائحة بها، وضــمان أن جميع احتياجات المناطق المعزولة متوفرة داخلها، وإعطاء منافذ الخبز والبدالين حصـ إضـافية حتى لا يضـطر السكان إلى الخروج خارج المناطق المعزولة. وعلى الرغم من أن مصر تستورد النسب الأكبر من احتياجاتها من الزيت، والقدح، واللحوم الحمراء إلا لإئ أن الوزارة لديها عقود لتأمين الاحتياجات منها، وكذلك تعمل على تتويع بلدان المنشأ الموردة لتلكي السلع حتى يُمكن إدارة الأزمة في حال تأثر تلك البلدان بالجائحة. 


\section{ملحق (2)}

مدى تأثر عمليات التسجيل التجاري

(مقابلة مع نائب رئيس جهاز تتمية التجارة الداخلية)

$$
14 \text { مايو } 2020
$$

أنثـأت الحكومة المصرية جهاز تتمية التجارة الداخلية بالقرار الجمهوري رقم 354 لسـنة 2008 لإدارة شـــئون التجارة الداخلية بالدولة (الجريدة الرســمية العدد 51 مكرر، 2008). يبلغ عدد مكاتب السجل التجاري المنتشرة في جميع أنحاء الجمهورية نحو 99 مكتب رئيسي في جميع أنحاء الجمهورية، بالإضـافة إلى 17 مكتباً ملحقاً بالغرف التجارية، ومكتب بالهيئة الاقتصادية لقناة السويس. و10 مكاتب ملحقة بالهيئة العامة للاستثمار وفروعها. والآن تتاح خدمة السجل التجارى من بوابة الخدمات الحكومية (وزارة التموين والتجارة الداخلية، 2020). وتوجد بالجهاز إدارات أخرى تتعلق أعمالها بالعلامات التجارية، والاســتثمارات في قطاع الأراضــي. وقد تأثرت أعمال الجهاز في بداية الأزمة، فتعطلت أعمال التسـجيل والرهن والتأثـير (إضـافة لرأس المال، إضافة شريك، مستخرج من السجل التجاري...). وانخفضت القوى العاملة بالجهاز نتيجة ارتفاع عدد حالات الأمراض المزمنة، ولكبر أعمار العاملين بالجهاز • وطالب المطورون لأكثر من 11

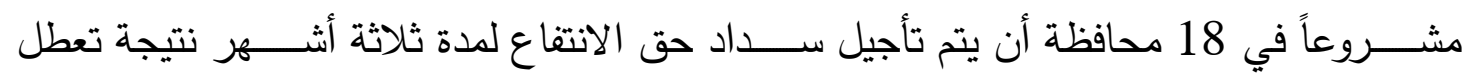
الأعمال. وبدأت مكاتب التسـجيل التجاري اعتباراً من 10 مايو العودة لأداء الخدمات بقوة العمل الكاملة دون تعليق أية خدمات. ويعمل الجهاز على تقديم 75\% من خدماته عبر الإنترنت. ويقوم الجهاز بإغلاق أي مكتب للتسـبيل التجاري في المناطق التي ظهرت بها حالات إصـابة

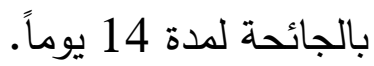




\section{ملحق (3)}

\section{دور مديريات التموين والتجارة الداخلية في ضبط الأسواق}

(مقابلة تليفونية مع معاون مدير مديرية التموين والتجارة الداخلية بمحافظة الإسكندرية)

$$
20
$$

بـدأت الأزمــة منـــ "نوة التتين" في 12 مـارس، والتي تم فيهـا الحرص على توفير احتيـاطي

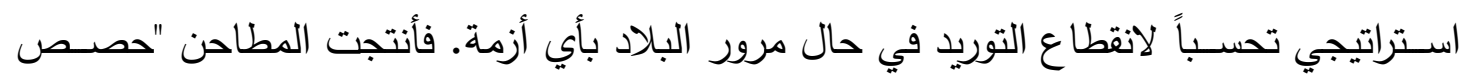
مزايدة" حتى يكون لاي كل مطدن رصـيد 2-3 أيام، وكل مطحن يعطى المخابز حصسة مزيدة لمدة 2-3 أيام أيضاً في أثناء الأزمات غير المتوقعة. وقامت المجمعات الاستهلاكية بدورها في توفير المنتجات بالكميات والجودة والأسـعار المناسبة، وتوفير السلع بأسعار تتافسية تقل 30\% عن السوق، وهذا الدور أعطى ثقة للمواطن بتوفر السلع، وردع المحتكرين عن فرض أسعار غير

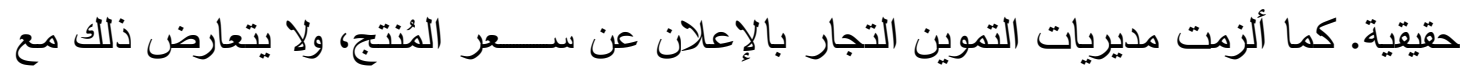

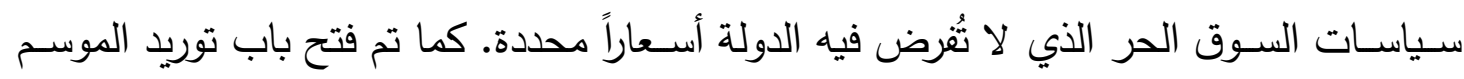
الجديد من القهح المحلي. ويوجد لدى المديرية مخزون لحم يكفي لما بعد العيد الكبير ، مع تحرير

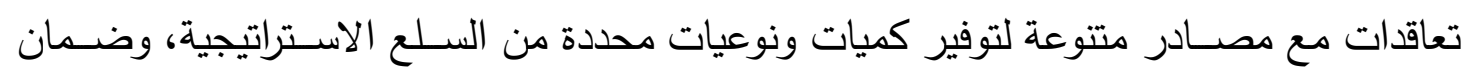

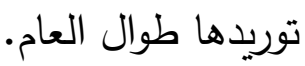

كما عرضت المجمعات الاستهلاكية لحوم برازيلي وسوداني بأسعار بلغت حوالي 90-100 جنيه وهي أسـعار تتافسية، وهو ما أدى إلى تحكم في أسـعار السوق في محلات الجزارة. وسـاعد في ذلك قرار وزير التموين رقم 330 لعام 2017 الذي ينص على إلزام كافة نقاط العرض والبيع

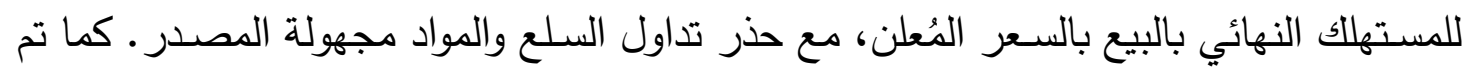
توفير المنتجات بكميات كافية في المجمعات الاستهلاكية التابعة لوزارة التموين والتجارة الداخلية. كما تم ضمان توفر الكحول الإيثيلي 70\%، والكمامات في الأسواق من خلال الحملات التفتيشية التي تعاونت فيها هيئات متعددة من وزارات مختلفة. ونظراً لانخفاض أعداد الموظفين بمديريـة التهرية التموين ســـواء لندرة أعدادهم في الأســـاس أو نتيجة لتطبيق قرار رئيس الوزراء بتخفيض أعداد العاملين ومنح أجازات لكبار الســن، وذوي الأمراض المزمنة، تعاونت مديرية التموين والتجارة الداخلية بالإنـــكندرية مع مديرية الطب البيطري، ووزارة الصــــة، وإدارة التفتيش الصــــيدلي، 
ومصلحة الرقابة الإدارية، مباحث التموين، جهاز حماية المستهلك، وأحياناً من مصلحة التهرب

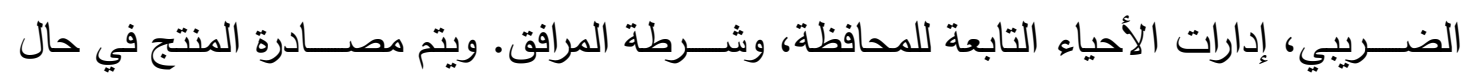
ضـبطها في مخازن غير مرخصـة. ومن أنواع المخالفات التي تم رصـــها: بيع الكحول الميثيلي

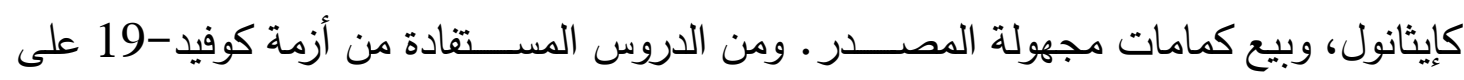
مستوى مديرية التموين والتجارة الداخلية بالإسكندرية:

- - العمل على زيادة المخزون الاستراتيجي، مع زيادة سعة المخازن. - - تدعيم التصـيع المحلي بالتنسـيق مع الوزارات والكيئات ذات الصـلة، مع زيادة الاعتماد

$$
\text { على التوريد الدحلي. }
$$

- اســتكمال التحول الرقمي الذي مكن مكاتب التموين من العمل آلياً وقت الجائحة لتمكن المواطنين من اســـتخراج بدل فاقد وتالف من المنزل لبطاقة التموين. وقد منع ذلك التكسس، وسـاعد كذلك في تنقية قواعد البيانات من غير المستحقين للدعم أو ممن سقط عنهم الدعم بالوفاة على سبيل المثال. - التعاون مع الهيئات والثــركات على مســتوى الوزارة الواحدة، مثل التعاون بين المديرية

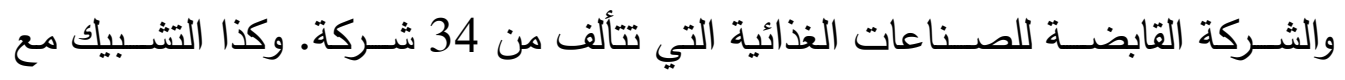
الهيئات بالوزارات الأخرى لتعويض نقص العمالة، وكذلك الاســتعانة بثـــباب الخريجين الذين يقومون بتأدية الخدمة العامة مقابل مكافأة تبلغ حوالي 750 شهرياً. - توسيع دائرة الضمان الاجتماعي لتشمل من هم ليسوا مستفيدين من الدعم التمويني، كما

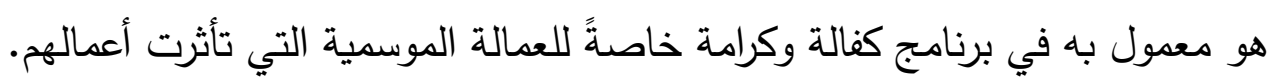




\section{ملحق (4)}

\section{تحليل جانبي العرض والطلب في المصانع كبيرة السعة لإنتاج الجبن}

(شركتان لإنتاج منتجات الألبان أحدها بالصالحية الجديدة محافظة الإسماعيلية، والأخرى بمركز

القناطر الخيرية بمحافظة القليوبية)

$$
12 \text { مايو } 2020
$$

الثـركتان محل الدراســة ينتجان الجبن الأبيض نباتي الدهن (الفيتا- الثلاجة)، والجبن المطبوخ،

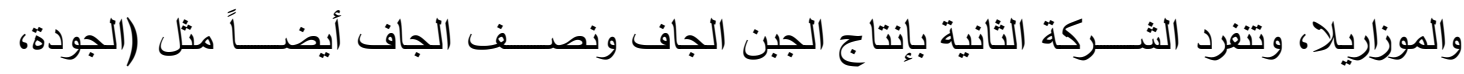

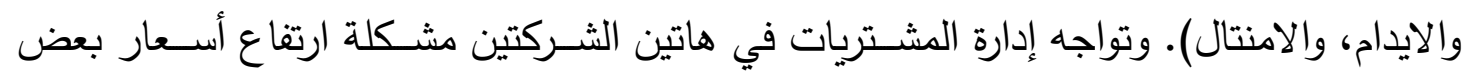
مكونات الإنتاج التي ليس لها بديل محلى مثل مادة "جلوكونو دلتا لاكتون" المستخدمة في إعطاء الطعم المميز للجبن الفيتا، والمواد الحافظة مثل ســوربات البوتاسـيوم، وغيرها من المسـتلزمات المسـتوردة (مثل المنافح الميكروبية، البادئات، ملح الليمون، وغيرها)، وإن كانت الكميات متوفرة. ويتوقع في حال اسـتمرار الأزمة إلى شـهر سـبتمبر أن تظهر أزمات في الإنتاج لعدم توفر بديل محلى. أما مسـتلزمات الإنتاج سخلاف اللبن الخام- التي لها بديل محلي فانخفضــت أسـعارها نتيجة انخفاض الطلب عليها في ظل غلق عدد من المصــــانع الكبرى التي ظهرت بها حالات إصـابة بكوفيد-19 في العاشر من رمضـان، والسـادس من أكتوبر ـ أما اللبن الخام فأصبح بديلاً للألبان المجففة التي يعتمد عليها إنتاج الشركات الكبرى، فارتفعت أسعاره نتيجة مزاحمة الشركات الكبرى الشركات الصغيرة والمتوسطة في الحصول عليه.

وتعمل المصـانع محل الدراسـة بنحو 50-75\% فقط من طاقتها التثـغيلية "المعتادة"، لأسـباب

- إما لانخفاض الوارد من الصين من مكونات أولية لازمة للتصنيع.

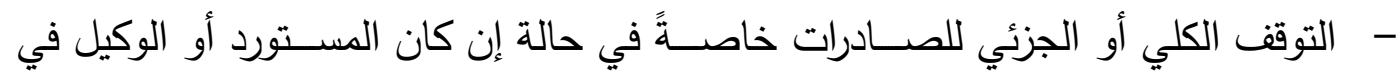

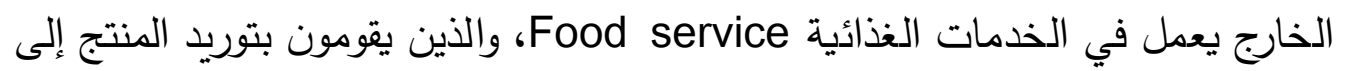
المطاعم والفنادق التي تأثرت أعمالها بثـــدة وقت الجائحة، وذلك بخلاف مراكز البيع المباشر للمستهلك Retailers الذين تأثروا إيجاباً بالجائحة. 
- - انخفاض الطلب المحلي نتيجة تأثر قطاع السـياحة، وتأثر المنشـآت المحلية العاملة في الخدمات الغذائية، والتي تورد منتجاتها إلى الفنادق والمطاعم.

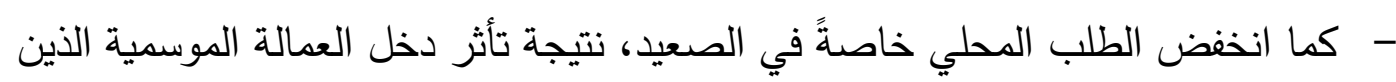

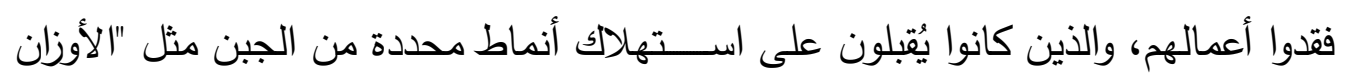
التسويقية من فئة 250 جم" التي تتناسب مع دخولهم المنخفضة. - - انخفاض الطاقة التثـــيلية نتيجة انخفاض قوة العمل بعد إعطاء إجازات لكبار الســن،

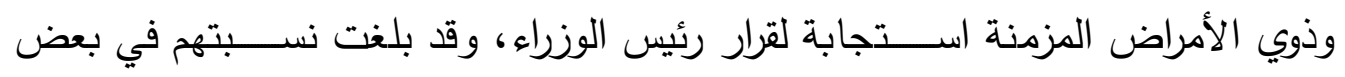

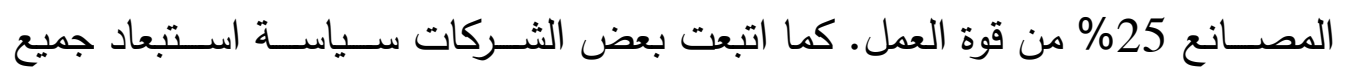
العاملين من القرى التي ظهرت بها حالات إصابة كإجراء احترازي داخلي.

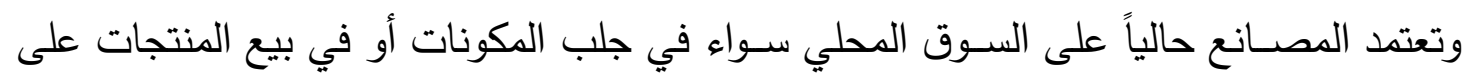
عكس الفترة مـا قبل أزمـة كوفيد-19 والتي كـان الاعتمـاد الأكبر على مســـتلزمـات الإنتاج المسـتوردة، وكان سـوق التصـدير يمثل من 30-80\% من حجم المبيعات في الثـركتين محل 


\section{ملحق (5)}

تحليل جانبي العرض والطلب في المشروعات الصغيرة المنتجة للجبن

(مشروعان لإنتاج الجبن الرومي والدمياطي أحدها بمحافظة البحيرة، والأخرى في محافظة الغربية)

$$
12 \text { مايو } 2020
$$

زادت المنافــة مع الثـركات الكبرى في الحصــول على اللبن الخام من المزارعين أو من مراكز

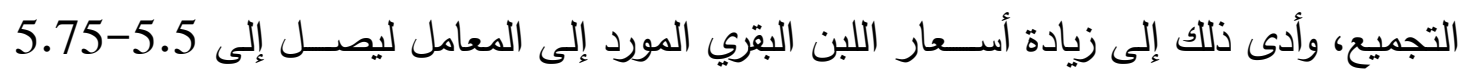
جنيه (4.2-4.3\% نسبة دسم) بعدما كان ثمنه 4.75-5.0 جنيهات للكيلو في الغربية والبحيرة،

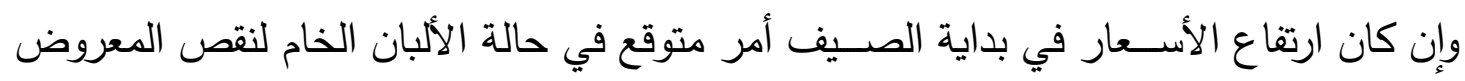
عند انتهاء موسم الحليب. وتواجه الدصانع الصغيرة الآن مشكلة نقص الطلب، فانخفضت نسبة الجبن الرومي الموجه إلى الثلاجات لتصـبح أقل من 10\% فقط من الإنتاج، وســ إحجام كثير

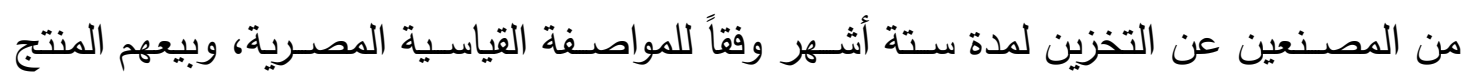
طازجاً دون تسويته، وذلك رغبة منهم في الحصـول على سـيولة نظير بيع المنتج غير المسـوى، وسيؤدي ذلك إلى نقص المعروض من الجبن الرومي العام القادم، وارتفاع أسعاره.

كما انخفض الإنتاج الســنـوي المتوقع من 5000 طرد إلى 500 طرد (الطرد أربع أقراص من الجبن، كل قرص 13 كجم في المتوســـ)، وذللك نظراً لانخفاض كميات اللبن الوارد الذي زاد

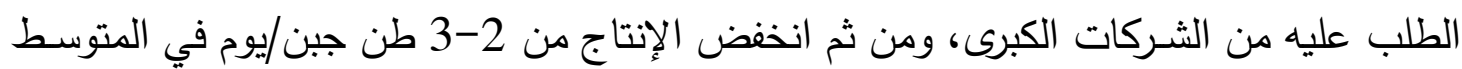

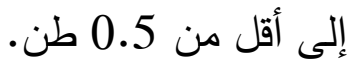




\section{ملحق (6)}

تحليل جانبي العرض والطلب في المصانع كبيرة السعة لإنتاج الألبان والعصائر

$$
\text { (شركة كبرى لمنتجات الألبان والعصائر - السادس من أكتوبر) }
$$

لم تتأثر الكميات أو أسـعار مستلزمات الإنتاج تأثراً معنوياً نتيجة الحظر لاستمرار عمل الموانئ والجمارك. وكذلك الحال لم يتأثر المعروض من اللبن الخام الذي تسـتلم الثــركة منه نحو 800 طن يومياً من مزارع مختلفة على مسـتوى الجمهورية. وإن كان هناك تخوف من ارتفاع أســعار المستلزمات نتيجة توقعات بارتفاع أسـعار الصـرف في الفترة القادمة نتيجة انخفاض الاحتياطي الاســتراتيجي من الدولار ، وهو ما أدى إلى شـــراء الثــركة المســتلزمات بكميات كبيرة، وإبرام

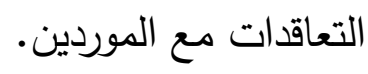

وتَّدر الثركة إلى ليبيا كأحد أسواقها الرئيسية، ولم يحدث تأثر يُذكر في حجم الصـادرات إليها حتى وقت الدراسة. أما السوق المحلي، فقد انخفض الطلب على العبوات سعة 250 مللى وجميع المنتجات ذات الاستخدام لمرة واحدة Single-serve بشدة بعد فرض الحظر وميل المستهلكين إلى اسـتهلاك المنتجات التي تسـخدم عدة مرات Multi-serve مثل المنتجات سـعة اللتر ـ وقد أدى ذلك إلى انخفاض الإنتاج بنسبة 50\% للعصبائر ، و 40\% للألبان. وكذلك فإن زيادة الطلب على المنتجات ذات الأحجام الأكبر في بداية الجائحة لم يستمر نظراً لشـراء المستهلكين لكميات كبيرة، وســرعان ما عاد الطلب إلى معدلاته الطبيعية. وهو الأمر الذي يعنى انخفاض الطاقة التشغيلية بنسبة من 40 إلى 50\%، وانخفاض المبيعات والتدفق النقدي للشركة بنفس النسبة. وتتوقع الشركة إن استمر الطلب المنخفض خلال فترة الصيف، وأثناء الفترة الففترض فيها العودة

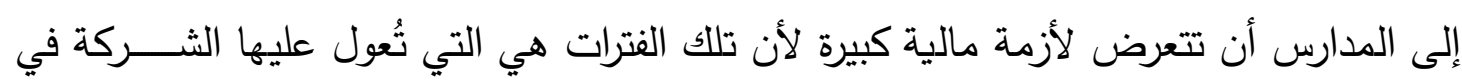
تحقيق أرباحها. وتأمل الشركة عودة الحياة الاقتصادية إلى مجراها المعتاد. 


\section{ملحق (7)}

\section{استقرار سلسلة توريد الغذاء لتجار الجملة والتجزئة}

(شركة استيراد وتوريد المنتجات الغذائية- جسر السويس، محافظة القاهرة)

$$
12 \text { مايو } 2020
$$

تتعامل الثركة في اللحوم (أسترالي، نيوزلندي)، كورند بيف Corned beef، الزبدة (من أيرلندا، وأحياناً مستوردين محليين)، الجبن الدنماركي (الثيدر، الريكفورد، الفلدنج). وجميع بلدان المنشـأ المذكورة لم تتعرض إلى آثار شديدة لجائحة كوفيد-19 حتى الآن. ولم تتأثر عملية الثـن، وإن

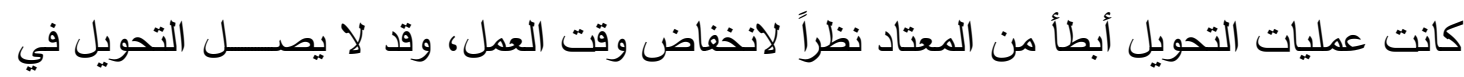
نفس اليوم. وقد أدى تقليص وقت أداء الخدمات الحكومية ليصــبح من 9 صـــباحاً إلى الواحدة ظهراً فقط إلى تقييد بعض المعاملات المالية في البنوك. كما أدى قرار البنك المركزي بوضـع حد للســب اليومي للنقود سـواء للأفراد أو الثـركات إلى تقليل نسـبي للسـيولة، وإن كانت لم تظهر أزمة نتيجة السـماح بالتعامل بالثـيكات أو التحويلات من حسـاب الثـركة إلى عملائها ومورديها وموظفيها. كما أن عملية النقل الداخلي لنقل المنتجات الواردة من الموانئ البحرية إلى مخازنها لم تتأثر لأن السيارات معها تصريح للسير وقت الحظر ـ وتتمتع جميع المواد الغذائية التي تستوردها الثـركة بالإعفاء من ضـريبة القيمة المضـافة ما عدا المسليات، والياميش، والكاجو ، وغيرها من المواد الغذائية غير الأساسية. وقد طبقت الثركة سياسـة التتاوب بين العاملين في بداية الأزمة، ومع استمرار الأزمة قررت الإدارة انتظام حضور جميع العاملين، والعمل بالوقت الكامل.

من المعتاد أن يبدأ موسـم رمضــان على المسـتوى اللوجسـتي في مثل هذه الثـركات ابتداء من رجب، فيتم استيراد وتجهيز الكميات المتوقع استهلاكها في رمضان. وقد انتابت المستهلكين في الثلث الأخير من مارس الماضي حالة من الذعر بعد بدء فرض الإجراءات الاحترازية، فبدأوا في

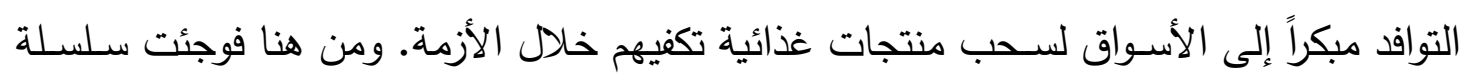
التوريد بأن ما تم توفيره للبيع في رمضان بدأ استنفاذه من المستهلكين في نهاية رجب. ولكن لأن ما تم شـراءه من المستهلكين يفوق حاجتهم، أصبـح الطلب في الموسـم أقل من المتوقع، خاصـةً عندما اسـتشـعر المسـتهلكون بعدم وجود أزمة، ورأوا أن المنتجات الغذائية الأســـــية متوفرة، فأحجموا عن التدافع لشـراء المزيد. وربما تسبب في ذلك، اتجاه المنتجين إلى زيادة إنتاجهم، فزاد 
العرض، وسادت حالة من الاطمئنان في الأسواق. كما ساهمت مبادرة "تحيا مصر" لتقديم كراتين رمضـان كمســولية مجتمعية من سـلسـلة التوريد بأسـعار مدعمة للمواطنين إلى زيادة اطمئنان المواطنين ذوي الدخول المنخفضـــة. وفي نفس الوقت، اســتفادت مراكز التســـويق الكبرى من

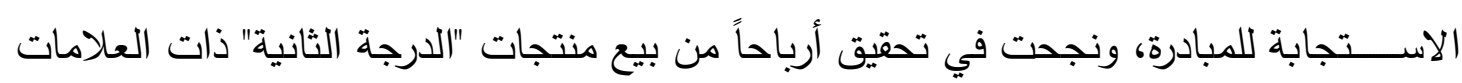
التجارية غير المعروفة الأرخص سعراً.

كانت أكثر الفئات التي تأثرت سلباً في سلسلة توريد الغذاء هم موردي الفنادق والمطاعم، والذين قاموا بإرجاع ما تم شراؤه إلى شركات الاستيراد مرة أخرى. ولم تتأثر شركات استيراد الأغذية بتالك ماتك المرتجعات نظراً لزيادة الطلب من عملائهم الأخرين الذين حققوا أرباحاً من الجائحة ممثلين في: تجار التجزئة ومحلات البقالة، والحسابات الرئيسية Key accounts أو الهايير ماركتس، وتجار الجملة. وجميع هذه الفئات الثلاث تأثرت مبيعاتها إيجاباً بالجائحة دون الحاجة إلى أنثطة ترويجية، وقد تبين ذلك من طريقة دفعهم المنتظمة، وانخفاض مرتجعاتهم.

وفي ظلل ذلك تتوقع شـركة اسـتيراد الأغذية عدم وجود تأثير سـلبي في حال اســمرار الجائحة طالما لا توجد إجراءات تضييق من الحكومة في إجراءات الاستيراد والموانئ والتحويلات البنكية. أما في حال تثديد الحكومة من الإجراءات الاحترازية أكثر من ذللك، فسيتأثر قطاع استيراد المواد الغذائية. ومع تزايد حالات الإصـابة بكوفيد-19 إذا استمرت الجائحة إلى سبتمبر ، ستزيد حالات إغلاق الأعمال، ومن ثم يزيد تسريح العمالة، فتنخفض القوة الشرائية، فيقل الطلب على المنتجات 